\title{
4E Analysis of Power and Water Cogeneration Plant based on Integrated MED- TVC and RO Desalination Units
}

\author{
H. Vazini Modabber ${ }^{1,2}, M$ H. Khoshgoftar Manesh ${ }^{1,2^{*}}$ \\ 1. Division of Thermal Science \& Energy Systems, Department of Mechanical Engineering, Faculty of \\ Technology \& Engineering, University of Qom, Qom, Iran \\ 2. Center of Environmental Research, University of Qom, Qom, Iran \\ E-mail: m.khoshgoftar@qom.ac.ir
}

Received 7 Sep 2019, Revised 18 Mar 2020, Accepted 11 Apr 2020

\begin{abstract}
In this study, integration of RO desalination unit with power and water cogeneration plant located in Qeshm Island in Iran has been investigated. The desalination unit exists in this plant is MED-TVC type. In this regard, energy, exergy, exergoeconomic, and exergoenvironmental (4E) analyses have been performed by developing a computer code using Matlab. Validation of thermodynamic data has been performed through comparing the results of modeling by Matlab with the simulation done in Thermoflex software and the real data gathered from the Qeshm cogeneration plant. The results show the acceptable accuracy of thermodynamic modeling. The exergoenvironmental analysis has been conducted based on Life Cycle Assessment (LCA). In this regard, the weight function of TVC is proposed in this paper based on technical data in different nominal sizes in order to estimate the environmental impacts of this component. The cogeneration plant produces $25.7 \mathrm{MW}$ power, consuming $6 \mathrm{~kg} / \mathrm{s}$ steam can lead to production of 51.7 $\mathrm{kg} / \mathrm{s}$ desalinated water. The gained output ratio (GOR) is about 8.7 for the MEDTVC unit. The performance ratio (PR) of RO desalination unit which is added to the downstream of MED-TVC has been calculated about 0.5. Integrating RO desalination unit with MED-TVC enhances the production of fresh water by 255.132 ton per hour.

Exergetic efficiency, total cost rate of the system and total environmental impact rate of the system has been calculated $46.86 \%, 64.01 \$ / \mathrm{min}$ and $29.49 \mathrm{pts} / \mathrm{min}$, respectively. Since the largest share of exergy destruction rate of the system belongs to the gas cycle and also Qeshm Island has a warm and muggy climate, adding a chiller type air cooling system to inlet of air compressor can decrease the power demand of air compressor and fuel consumption of combustion chamber which makes the system more efficient and reduce the cost and environmental impact rate of the system.
\end{abstract}

Keywords: Cogeneration; MEDTVC desalination; RO desalination; exergy analysis; exergoeconomic analysis; Life Cycle Assessment.

\section{Introduction}

Life, health, and sustainable development, require Freshwater. Man is in urgent need of rivers, lakes, and aquifers to meet the needs of drinking, agriculture, and industry. There are two main problems with the use of these freshwater sources. One of the issues is the pollution of rivers and lakes from domestic and industrial waste, and wastewater, and the problem of non-uniform distribution of these resources in different parts of the world, the oceans are the largest reservoirs of water. However, using about $3.5 \%$ by weight of different salts, direct use of these waters is not possible [1-7].

Freshwater means water that contains less than 1000 milligrams of salinity per liter of water [8]. However, most of the water present on the surface of the earth has a salinity of up to $10,000 \mathrm{ppm}$, and the free water is usually salinity in the range of $35,000 \mathrm{ppm}$ to $45,000 \mathrm{ppm}$ in the form of salts dissolved in water [9]. Our country is no exception. On the other hand, the shortage of Freshwater resources in Iran and, on the other hand, access to saltwater resources of the Persian Gulf in the south, and the Caspian Sea in the north, necessitate the need for Freshwater supply from these resources for industrial, and domestic uses.

The issue of Desalination has attracted attention in most countries of the world in recent years. Today, over 15,000 units of desalinating water unit are operating around the world. The Middle East accounts for roughly $50 \%$ of the world's total freshwater production. Saudi Arabia, with about $26 \%$ of world freshwater production capacity, is the largest producer in the industry, and the United States with 17\% is in the next category. In Saudi Arabia, thermal water desalination is most used. [8] The process of separating salt from saline water, like any other process, requires energy, and the amount of this energy is different for different methods of desalination. In a particular process, the amount of energy per unit volume of Freshwater produced depends on the chemical composition and degree of impurities of saline water and its thermodynamic characteristics [10]. Lack of energy, and high and continuous costs of energy supply, increased energy consumption, environmental pollution due to the consumption of fossil fuels and the deterioration of fossil fuels have led to issues of energy 
recovery in industrial and process units in recent years [11-15]. The reason for this is that, firstly, because of the harm caused by seawater salinity for water pipes, the vulnerability and corrosion of the transmission equipment rises. Secondly, if water desalination takes place in the south plateau, the demand of Freshwater in this region can be solved. As a result, desalination is carried out at the seaside, the wastewater is transferred to the sea after desalination and released to the proper depth, and then the desalinated water is transferred to the plateau.

Over the years, extensive researches have been done on power generation and desalination systems. Tadros assessed the combination of multi-stage flash (MSF) desalination unit with a variety of steam turbines, a gas turbine and a boiler, in 1979. An optimization process was performed on this system thermo economically. The results showed that a single unit of MSF can produce up to $1400 \mathrm{~m}^{3} / \mathrm{h}$ freshwater [16].

In 1997, Darwish et al. Used Exergy analysis to determine the cost and amount of energy consumed in the cogeneration system for the production of freshwater and power. To compare the energy consumption and cost, a variety of desalination methods such as multi-effect desalination (MED) using Thermal vapor compressor (TVC), mechanical vapor compressor (MVC), and reverse osmosis (RO) was investigated[17].

The cogeneration system including desalination and power production units was analyzed in terms of economics and energy by wade in 1999. In this research, gas turbine power plant, combined cycle, steam cycle and their interconnections with MSF and RO desalination units have been investigated using the reference cycle method. The amount of energy allocated to produce Freshwater was studied, and MSF type was used as desalination system. The results showed that the MSF with combined cycle power plant has the minimum cost allocation between all cases [18].

Dervish et al. in 2004 suggested the use of gas turbines for Freshwater in Kuwait, due to the lack of enough freshwater in this country. They investigated several different combinations of gas turbine cycle and multi-stage flash desalinating system with a sudden drop in pressure and oscilloscope [19].

In 2004, Cardona and Piacentino conducted a research to provide the optimal design of water and energy generation units simultaneously. They investigated reverse osmosis and thermal desalination system with a sudden drop in pressure to improve the system's performance. They emphasized that the produced electrical energy could also be used to set up reverse osmosis, and the auxiliary equipment, and tried to provide a measure based on exergo-economics, and profit history for optimal design of such units. Also, a thermoeconomic optimization process was performed in order to minimize the cost of each component [20].

In 2006, Wang et al. began their work on the integration of the MED-desalination system and gas turbine power plant. The heat required for the desalination unit was afforded using waste heat of gas cycle. In that same year, he examined the gas turbine cycle by injecting steam, and connecting it with thermal water desalination. Using a recovery boiler, the steam needed to be injected into the combustion chamber was produced. They concluded that the injection rate of steam would have a profound effect on water and power production. This increase would enhance the production of power but it reduced the freshwater production. On the other hand, increasing the inlet temperature of gas turbine would increase the power and water production [21].

In 2007, Wang et al. carried out another study on the gas turbine power plant by injecting steam into the desalination unit in order to design another cogeneration system. From the analysis of two different cycles in the previous and current research, they concluded that the fuel consumption for the production of freshwater during the steam injection process is $45 \%$ of total fuel, and in the wet air injection cycle, that is $31 \%$ to $54 \%$ of total fuel consumption in MEDTVC unit [22].

In 2009, Khoshgoftar Manesh et al. performed a thermodynamic analysis and multi-objective optimization of the combined heat and power generation system with a thermal desalination unit and nuclear reactor[23].

In 2012, Amidpour et al. reviewed and optimized the integration of MED-TVC system with a gas cycle power plant. The results showed that the evaporator has the maximum exergy destruction in the plant. in the very high-pressure steam injection of 30 bars, the minimum cost of desalinated water occurred in the MED-TVC unit [24].

In 2014, Alzahrani et al. investigated a gas turbine cycle integrated with MED-TVC and RO desalination units. An energy recovery system connected the thermal desalination unit to the gas turbine cycle. An exergy analysis was performed to evaluate the destruction of each component. Effect No.4 of the MED thermal desalination unit had $45 \%$ of the total exergy destruction [25].

Exergetic and economic evaluation of distillation hybrid configurations for bioethanol refining was carried out by Suleiman et al [26] in 2014. They showed that the THIDC extraction sequences were better than the azeotropic distillation derived hybrids thermodynamically and economically. It was concluded that that the less energy consuming process might not necessarily be the most efficient configuration.

In 2015, thermo-economic model of a superstructure combined cogeneration power plant was studied by Hanafi et al [27]. They proposed the optimum design of the system based on maximum production of power and water. It was found out that the combined cogeneration system, including gas and stream cycles and MED-TVC desalination system can save about $20.6 \%$ of Total Annual Cost "TAC" compared with separate power and water production system.

In 2015, Eshoul et al. considered a combined cycle power plant standalone and integrated with a MED-TVC desalination unit. They performed thermodynamic and exergy analyses on these case studies. Also, the amount of the environmental impact of carbon dioxide emission was obtained and. The results showed that the emission rises by increasing the ambient air temperature. Every $10^{\circ} \mathrm{C}$ increase in the ambient air temperature rises the plant efficiency about $0.42 \%$ and decrease the output power about $5.3 \%$ [28].

In 2016, Suleiman et al [29] conducted the exergy and exergoeconomic analyses to evaluate proton exchange membrane fuel cell (PEMFC) using methanol and methane as fuel sources. They found out the burner, stack 
and steam reformer had the highest rate of irreversibility. Considering energy, exergy and economic analysis, methane system configuration was selected as the best preferred choice of PEMC configuration.

In 2018, Eshoul et al. has investigated a MED-TVC desalination unit. They used the energetic, exergetic, and economic analyses to study the system. The results showed that the Thermocompressor is the main source of the exergy destruction in this cite. By using a preheater in this system, the cost of the desalinated water was decreased [30].

Energy, exergy, economic and environmental analysis of a proposed municipal waste driven power plant was assessed by Owebor et al [31] in 2019. Combustion chamber had the largest amount of exergy destruction rate of $37 \%$. They showed that the waste-toenergy conversion system has the potentials for providing affordable and clean energy in the developing nations, especially in the Sub-Saharan Africa countries.

In 2019, Esmaeilzadehazimi et al [32] performed 4E analysis on a combined cycle power plant integrated with magneto hydrodynamic generator. They observed that this integration leads to higher efficiency of the combined cycle and lower emission rate of the pollutants and cost rate of the exergy destruction of the components.

Since the production of Freshwater simultaneously with the increase in the population of different regions is always one of the most important industrial issues, the use of water desalination technology can be one of the most effective ways of utilizing the heat recovery of power plants. Dual-use systems for the simultaneous production of Freshwater, and power include two important sections, thermal power plants, and water desalination units [33-35]. In fact, the thermal power plant also has the task of generating the required electrical energy, as well as the task of supplying the energy needed to start the desalinating unit. As mentioned, Iran also has a high potential for using this technology, given the need for Freshwater, and the presence of numerous thermal power plants in the north, and south coastal regions. In recent years, discussions have been held on the need for water supply in the central regions of Iran to develop water supply, agriculture, and industry, as well as to provide investment attraction in the south of the country. The main purpose of the project is to supply the water resources needed in the central and south parts of the country, which have no access to water in terms of climate and land, and for this reason they have been deprived of development and access to new investments over the years. In order to prevent unbalanced development in the country and make possible the use of opportunities for wealth production in the south of Iran, supply of water to industrial, and mining enterprises and, in general, expansion, and development in the south regions, the desalination, and transfer of Persian Gulf water to the Central Plateau Iran has been planning, and implementing. There is no accurate investigation about integration of desalination unit with combined cycle power plant.

In this regard, Qeshm power and water cogeneration plant working with the gas turbine, HRSG and MEDTVC has been selected as a real case study. The integration of RO to the existing plant has been proposed and investigated. To better understanding of the performance of the proposed system, $4 \mathrm{E}$ analysis has been used. The exergoenvironmental analysis has been performed based on Life Cycle Assessment. Moreover, a new correlation has been presented for TVC unit.

\section{Case Study}

Qeshm power plant is a combined cycle type which includes gas and steam cycles. Using the recovery boiler, the heat in the exhaust gases of gas turbine is used to generate steam required in steam cycle. If the gas turbine is not a hybrid cycle, its exhaust gases, which can withstand temperatures of up to $600{ }^{\circ} \mathrm{C}$, enter directly into the air, and the remaining energy is wasted. While in the combined cycle power plant, this energy is utilized, and the boiler generates steam without fuel consumption; hence, the efficiency of the system increases.

Multi-effect distillation (MED) technology was used in the late 1950s, and early 1960s. Multi-stage distillation is performed in several tubes, and ducts, which are known as "effect", and use the principles of evaporation, and distillation at low-pressures for their activity. In this technology, there are a number of steam vapor conduits horizontally or vertically, where pressure is gradually reduced. This process uses the fact that water is boiling at lower pressures at lower temperatures. Therefore, the water vapor in the first duct will provide the heat needed for the second duct, and this process continues until the last duct.

The principles of the Thermocompressor (TVC) are similar to other steam ejectors. Using high-pressure steam, the vapors from the condensation process, evaporation, etc. are compressed, compressed, and released at a higher pressure. This drain usually takes place in the condenser. The Thermocompressor is used in some condensing equipment as a heat pump to recycle heat energy. In this case, this component motivates a portion of the steam which is generated at the last stage of the condensing process. Due to its low temperature, the generated steam needs to be motivated. Using thermal vapor compressor reduces steam and water consumption significantly. Schematic of a thermal vapor compressor has been shown in the figure 1 .

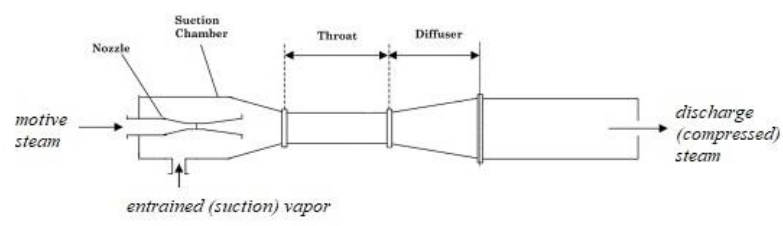

Figure 1. Schematic of Thermal Vapor Compressor

The MED-TVC works as an MED system coupled with a thermal vapor compressor. The purpose of TVC is to take advantage of the pressure of the available steam to enhance the unit's performance, as this pressure is sufficient (i.e. above two bar abs). The figure 2 shows a base schematic of the MED-TVC desalination process.

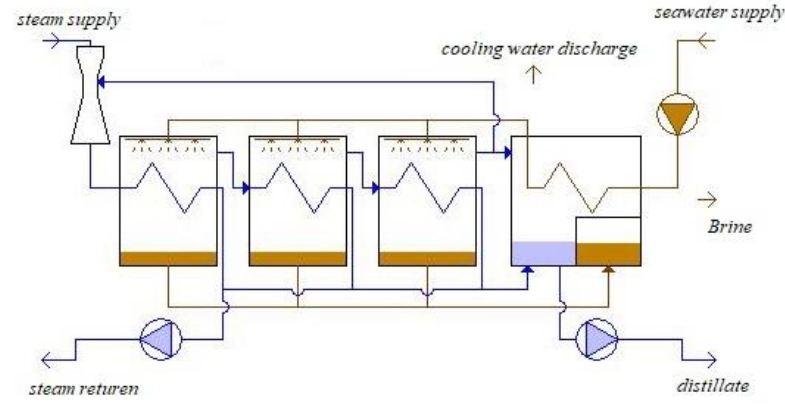

Figure 2. Schematic of MED-TVC desalination system 
In the process of desalinating the water by membrane method, brine is passed through the nanometer membranes by high pressure. These membranes act like a filter, and make it desalted by separating the impurities of the water. The reverse osmosis (RO), a type of membrane desalination, is the most commonly used method of desalination in the world. The advantage of this method in comparison with the thermal methods is that it does not require thermal energy to desalt the water, but it consumes more electricity. Schematic of a RO unit has been presented in the figure 3 .

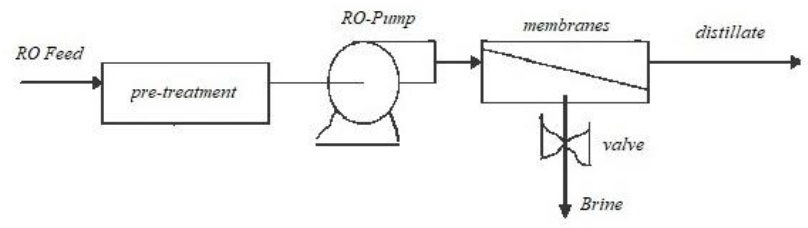

Figure 3. Schematic of the RO desalination system

A gas turbine power cycle can be coupled to the distillation unit, if the thermal energy from the turbine exhaust for the production of low-pressure steam is used in the boiler. This boiler is also called the Heat Recovery Steam Generator (HRSG). Auxiliary boilers are often installed to ensure that water desalination is able to continue to operate in the event of a power failure.

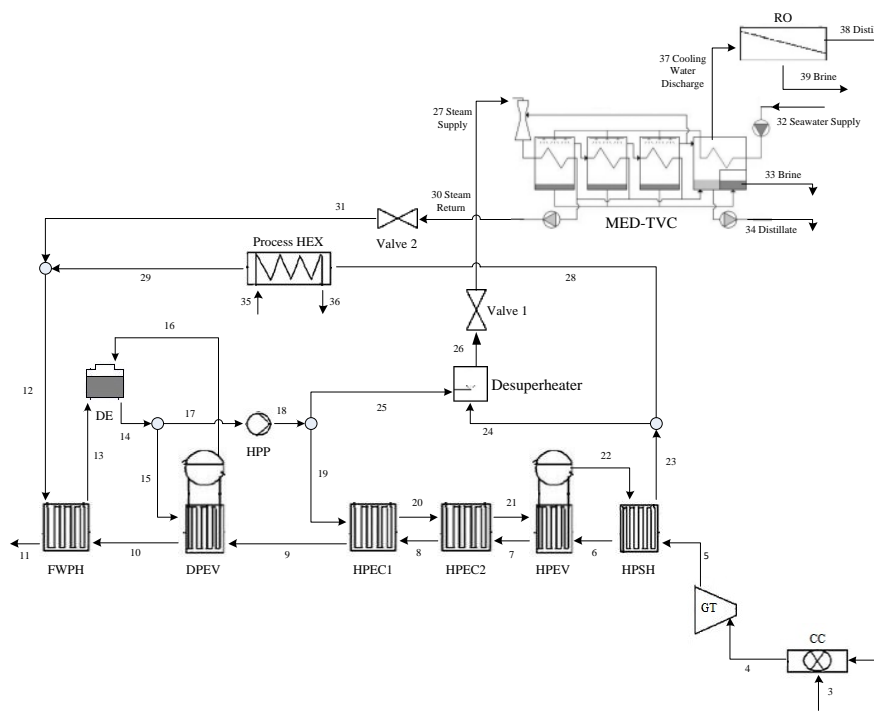

Figure 4. Schematic of the multi-generation combined cycle power plant

It is viable to combine gas and steam cycles to improve their thermodynamic performance, and this structure is called a combined cycle. In this research, gas cycle is connected to generator to produce electrical power, while in steam cycle, the thermal power generated is at hand. The process of desalinating can be coupled with a combined cycle power plant, in which case the steam generated by the heat recovery steam generator will be used. Qeshm combined cycle power plant is integrated with MED-TVC system. Adding a RO desalination unit to the downstream of MED-TVC has been performed in this study. The schematic of this combined cycle has been presented in figure 4. Also, the technical characteristics of the cogeneration combined cycle power plant are indicated in the table 1 .
Table 1. Technical characteristics of the multi-generation combined cycle power plant

\begin{tabular}{lll}
\hline Parameter & Unit & Value \\
\hline Site Level & $\mathrm{m}$ & 302.0 \\
Air Compression ratio & - & 19.23 \\
Ambient Temperature & $\mathrm{C}$ & 35.00 \\
Net Power Output of Gas & $\mathrm{MW}$ & 25.67 \\
Cycle & & \\
Isentropic Efficiency of AC & $\%$ & 90.00 \\
Isentropic Efficiency of GT & $\%$ & 93.00 \\
Efficiency of CC & $\%$ & 99.00 \\
Turbine Inlet Temperature & $\mathrm{C}$ & 1232 \\
Fuel Type & - & $\mathrm{NG}$ \\
MED NO. of Effects & - & 5 \\
MED Distillate Flow Rate & ton/h & 186.2 \\
Salinity of Seawater & $\mathrm{g} / \mathrm{Kg}$ & 38.7 \\
MED Recovery Ratio & - & 0.2957 \\
HRSG High-pressure & bar & 53.3 \\
\hline
\end{tabular}

\section{Methodology}

\subsection{Thermodynamic Analysis}

Thermodynamics is a branch of the natural sciences that discusses heat, and its relation to energy, and labor, and has four fundamental laws. The thermodynamics of macroscopic variables (such as temperature, internal energy, entropy, and pressure) are used to describe the state of the materials of the definition and how they relate to them, and the rules governing them. Thermodynamics expresses the average behavior of a large number of microscopic particles. The rule that governs thermodynamics can be obtained through statistical mechanics. Thermodynamics is a large part of science, and engineering. Thermodynamics means studying energy, turning energy into different modes, and the ability to work energy. At first, three thermodynamic laws were drafted, but according to the fourth law, the so-called zeroth law was called, because the law had one, two, three, and it was not a fundamental principle.

Many power plants and heat engines generate useful wark by converting energy. In all of them, energy translates into a mechanical component and leads to the production of whork. This energy conversion is based on the first law of thermodynamics. The first law states in general terms that energy, and matter do not come into existence, and disappear. The only form of solid, liquid, gas, and plasma changes, and the input of each machine with its output equals. In other words, the internal energy change of the closed system is equal to the added temperature minus the pure work that the machine does because the system works in the real world, there is always some energy transferred to the outside environment (energy dissipation), this leads to inadequacy, and The second law was created to conceal the defect of the first law.

The second law of thermodynamics necessarily states that one cannot get a process in which the unique effect is actually to deduct a positive heat from a source, and produce a positive one. In this case, the energy or temperature does not go up to the object more warmly than the cooler object. Mass and energy balances for each component are shown as equation (1) \& (2) [36, 37]:

$$
\begin{aligned}
& \dot{m}_{\text {in }}-\dot{m}_{\text {out }}=0 \\
& \dot{E}_{\text {in }}-\dot{E}_{\text {out }}=0
\end{aligned}
$$


The base thermodynamic equations of each component are presented in table 2, 3, 4, and 5 as follow.

The number of equations concerned with the water desalination unit which must be solved simultaneously is relatively large; because of the variety of simultaneous operations exist in MED-TVC unit. Hence, it increases the number of involved equations. On the other hand, the number of effects is inserted into the analysis by the user as an input. This makes the coding process more complicated, and it requires more flexibility. As user decides to change the number of effects, the number of equations which need to be solved simultaneously differs. Therefore, in order to provide this flexibility, MED modeling process is performed in the EES software environment. Nevertheless, the rest of programming has been done in the MATLAB software. This decision is causing a disruption in the simultaneous implementation of the code developed in both MATLAB and EES, which is not desirable; because we intend to analyze all parts of the system simultaneously with the implementation of the model, so that the results of one part can effect on the other sections. In order to solve this problem, the MACRO coding environment of the EES software utilizes the interfacing between these two types of software. In this way, when the developed model is implemented in MATLAB software, the instruction to run EES software which includes modeling MED water desalination unit is issued by the MACRO programming environment. Thus, by running the MATLAB software, EES file is executed, and the problem described is going to be solved by interaction of MATLAB and EES.

\subsection{Exergy Analysis}

The potential of a system that only has a heat exchange to environment is called its exergy or thermodynamic access to its dead state. In fact, Exergy is the maximum useful work that can be obtained from a material stream or energy: as stated, useful work will be maximized if the process is reversible. Therefore, there is a relationship between the reversible work wand the exergy. The physical and chemical exergy values of a material stream can be calculated using the equation (3) \& (4).

The specific chemical exergy for methane can be obtained as equation (5) [36].

$$
\begin{aligned}
& e x^{P H}=\left(h-h_{0}\right)-T_{0}\left(\mathrm{~s}-\mathrm{s}_{0}\right) \\
& e x^{C H}=\sum x_{k} e \bar{x}_{k}^{C H}+\bar{R} T_{0} \sum x_{k} \ln \left(\mathrm{x}_{k}\right) \\
& e x_{\text {methane }}^{C H}=1.037 \times L H V_{\text {methane }}
\end{aligned}
$$

The chemical exergy of seawater streams (molar basis) in $\mathrm{kJ} / \mathrm{kmol}$ is given as follow [38, 39]:

$$
e \bar{x}_{s w}^{C H}=n_{s}\left(\bar{\mu}_{s}-\bar{\mu}_{s}^{0}\right)-n_{w}\left(\bar{\mu}_{w}-\bar{\mu}_{w}^{0}\right)
$$

Which $n_{s}$ is moles number of salt in seawater and $n_{w}$ is that of water.

Moreover, $\bar{\mu}_{s}$ is molar chemical potential of salt in seawater in $\mathrm{kJ} / \mathrm{kmol}$, and $\bar{\mu}_{w}$ is that of water.
The superscript zero indicates the global dead state so that $\mu^{0}=f\left(\mathrm{P}_{0}, \mathrm{~T}_{0}\right.$, salinity $\left._{0}\right)$ and salinity $_{0}=$ salinity $_{\text {feed }}$.

The chemical exergy of seawater streams (mass basis) can be obtained in $\mathrm{kJ} / \mathrm{kg}[38,39]$ :

$e x_{s w}^{C H}=m f_{s}\left(\mu_{s}^{*}-\mu_{s}^{0}\right)-m f_{w}\left(\mu_{w}^{*}-\mu_{w}^{0}\right)$

Which $m f_{s}$ is mass fraction of salt in seawater, and $m f_{w}$ is that of water.

Moreover, $\mu_{s}^{*}$ is chemical potential of salt in seawater in $\mathrm{kJ} / \mathrm{kg}$ at restricted dead state condition, and $\mu_{w}^{*}$ is that of water.

The superscript $*$ indicates the restricted dead state so that $\mu^{*}=f\left(\mathrm{P}_{0}, \mathrm{~T}_{0}\right.$, salinity $\left._{\mathrm{i} \text {-th stream }}\right)$.

The total exergy of a material stream is given as follow $[36,37]$ :

$$
e x_{i}=e x_{i}^{C H}+e x_{i}^{P H}
$$

The exergy rate of the material streams can be determined as follow $[36,37]$ :

$\dot{E} x_{i}=\dot{m}_{i} \times e x_{i}$

The exergy destruction rate and exergetic efficiency of each component can be calculated by equation 10 and 11 [36, 37].

$$
\begin{aligned}
& \dot{E} x_{D, k}=\dot{E} x_{\mathrm{F}, k}-\dot{E} x_{\mathrm{P}, k} \\
& \varepsilon_{k}=\frac{\dot{E} x_{P, k}}{\dot{E} x_{\mathrm{F}, k}}
\end{aligned}
$$

The fuel and product exergy rates are two important parameters which can be defined in each component of the cycle. Table 6 shows the equations of exergy rate of the fuel and product streams in the equipment.

\subsection{Exergoeconomic Analysis}

Exergoeconomic or thermoeconomic is a branch of engineering that combines exergy analysis with economic principles; thus, this provides information that is not available through routine analysis of energy, and economic research for the designers of the system. In the engineering problems, it is quite crucial to consider the thermodynamic and the economic views simultaneously. The objectives of exergoeconomic analysis include the calculation of the costs of the system's products, cost of exergy destruction, the material and energy streams' cost rate and cost per exergy unit and total cost rate of the system.

Different methods have been proposed for exergycosmetic analysis. In this research, a special cost method for exergy has been used. This cost-based approach to exergy units, exergy efficiency, and auxiliary equations for different components of the thermal system is based. This method involves the identification of exergy flows, the fuel and product for each component of the thermal system.

In Exergy pricing, a cost is assigned to each exergy stream. These streams include the exergy transmitted by the inlets and outlets. Table 7 shows the equations of purchased cost for the equipment. 
Table 2. Equations, inputs and outputs of the equipment of gas cycle

\begin{tabular}{|c|c|c|c|}
\hline Component & Equations & inputs & outputs \\
\hline Air Compressor & $\begin{array}{l}W_{A C}=\dot{m}_{\text {air }}\left(\mathrm{h}_{2}-\mathrm{h}_{1}\right) \\
\mathrm{T}_{1}=T_{0} \\
P_{1}=P_{0} \\
P_{2}=P_{1} \times r_{p, A C} \\
T_{2}=T_{1}\left\{1+\frac{1}{\eta_{A C}}\left[\mathrm{r}_{p, A C}^{\frac{\gamma_{\text {air }}-1}{\gamma_{\text {air }}}}-1\right]\right\} \\
h_{1}=h_{\text {air } @ T_{1}}, h_{2}=h_{\text {air } @ T_{2}}\end{array}$ & $\begin{array}{l}T_{0}, \mathrm{P}_{0} \\
r_{p, A C} \\
\eta_{A C} \\
\gamma_{a i r}\end{array}$ & $\begin{array}{l}W_{A C} \\
\dot{m}_{\text {air }} \\
T_{2}, P_{2}\end{array}$ \\
\hline Combustion Chamber & $\begin{array}{l}\dot{m}_{\text {air }} h_{2}+\dot{m}_{\text {fuel }} L H V_{\text {fuel }} \eta_{C C}-\dot{m}_{f g} h_{4}=0 \\
\dot{m}_{\text {air }}+\dot{m}_{\text {fuel }}-\dot{m}_{f g}=0 \\
P_{4}=P_{2}\left(1-\Delta \mathrm{P}_{C C}\right) \\
h_{4}=h_{\mathrm{fg} @ T_{4}}\end{array}$ & $\begin{array}{l}L H V_{\text {fuel }}, \eta_{C C} \\
\Delta P_{C C} \\
T_{2}, P_{2}, \dot{m}_{\text {air }}\end{array}$ & $\begin{array}{l}Q_{C C} \\
T_{4}, P_{4} \\
\dot{m}_{f u e l}, \dot{m}_{f g}\end{array}$ \\
\hline Gas Turbine & $\begin{array}{l}W_{G T}=\dot{m}_{f g}\left(h_{4}-h_{5}\right) \\
T_{5}=T_{4}\left\{1-\eta_{G T}\left[1-\mathrm{r}_{p, G T}^{\frac{1-\gamma_{f g}}{\gamma_{f g}}}\right]\right\} \\
r_{p, G T}=P_{4} / \mathrm{P}_{5} \\
P_{5}=P_{0}+\sum \Delta P_{H R S G, f g} \\
W_{n e t, g c}=W_{G T}-W_{A C} \\
h_{5}=h_{\mathrm{fg} @ T_{5}}\end{array}$ & $\begin{array}{l}\eta_{G T} \\
T_{4}, P_{4}, \dot{m}_{f g} \\
W_{n e t, g c} \\
W_{A C}\end{array}$ & $\begin{array}{l}W_{G T} \\
T_{5}\end{array}$ \\
\hline
\end{tabular}

Table 3. Equations, inputs and outputs of the equipment of steam side

\begin{tabular}{|c|c|c|c|c|}
\hline$\overline{\text { Component }}$ & Equations & & inputs & outputs \\
\hline High-Pressure Super heater & $\begin{array}{l}\dot{m}_{f g}\left(h_{5}-h_{6}\right)+\dot{m}_{\text {hrsg }}\left(h_{22}-\mathrm{h}_{23}\right)=0 \\
P_{6}=P_{5}-\Delta P_{H P S H, \mathrm{fg}} \\
P_{23}=P_{22}-\Delta P_{H P S H, \mathrm{~s}} \\
T_{23}=T_{\text {sat }, H P S H}+T_{\text {sup }, H P S H} \\
Q_{H P S H}=\dot{m}_{\text {hrsg }}\left(\mathrm{h}_{23}-\mathrm{h}_{22}\right) \\
h_{6}=h_{\mathrm{fg} @ T_{6}}, \mathrm{~h}_{23}=h_{\text {water } @ T_{23}, P_{23}}\end{array}$ & {$[37,38]$} & $\begin{array}{l}\dot{m}_{f g}, T_{5}, P_{5} \\
\Delta P_{H P S H, f g} \\
\Delta P_{H P S H, \mathrm{~s}} \\
T_{\text {sup }, H P S H} \\
T_{22}, P_{22}\end{array}$ & $\begin{array}{l}Q_{H P S H} \\
T_{6}, P_{6} \\
T_{23}, P_{23} \\
\dot{m}_{\text {hrs }}\end{array}$ \\
\hline High-Pressure Evaporator & $\begin{array}{l}\dot{m}_{f g}\left(h_{6}-h_{7}\right)+\dot{m}_{\text {hrsg }}\left(h_{21}-\mathrm{h}_{22}\right)=0 \\
P_{7}=P_{6}-\Delta P_{H P E V, \mathrm{fg}} \\
P_{22}=P_{21}-\Delta P_{H P E V, \mathrm{~s}} \\
T_{22}=T_{\text {sat } @ P_{22}} \\
Q_{H P E V}=\dot{m}_{\text {hrsg }}\left(\mathrm{h}_{22}-\mathrm{h}_{21}\right) \\
h_{7}=h_{\mathrm{fg} @ T_{7}}, \mathrm{~h}_{22}=h_{g, \text { water } @ P_{22}}\end{array}$ & {$[37,38]$} & $\begin{array}{l}\dot{m}_{f g}, T_{6}, P_{6} \\
\Delta P_{H P E V, f g} \\
\Delta P_{H P E V, \mathrm{~s}} \\
T_{21}, P_{21}\end{array}$ & $\begin{array}{l}Q_{H P E V} \\
T_{7}, P_{7} \\
T_{22}, P_{22} \\
\dot{m}_{h r s g}\end{array}$ \\
\hline
\end{tabular}


Table 3. Equations, inputs and outputs of the equipment of steam side (Continued)

\begin{tabular}{|c|c|c|c|c|}
\hline Component & Equations & & inputs & outputs \\
\hline High-Pressure Economizer 2 & $\begin{array}{l}\dot{m}_{f g}\left(h_{7}-h_{8}\right)+\dot{m}_{\text {hrsg }}\left(h_{20}-\mathrm{h}_{21}\right)=0 \\
P_{8}=P_{7}-\Delta P_{H P E C 2, \mathrm{fg}} \\
P_{21}=P_{20}-\Delta P_{H P E C 2, \mathrm{~s}} \\
T_{21}=T_{\text {sat }, H P E C 2}-T_{\text {sub }, H P E C 2} \\
Q_{H P E C 2}=\dot{m}_{\text {hrsg }}\left(\mathrm{h}_{21}-\mathrm{h}_{20}\right) \\
h_{8}=h_{\text {fg@ } @ 8}, \mathrm{~h}_{21}=h_{\text {water } @ P_{21}, T_{21}}\end{array}$ & {$[37,38]$} & $\begin{array}{l}\dot{m}_{f g}, T_{7}, P_{7} \\
\Delta P_{H P E C 2, f g} \\
\Delta P_{H P E C 2, \mathrm{~s}} \\
T_{20}, P_{20} \\
T_{s u b, H P E C 2}\end{array}$ & $\begin{array}{l}Q_{H P E C 2} \\
T_{8}, P_{8} \\
T_{21}, P_{21} \\
\dot{m}_{h r s g}\end{array}$ \\
\hline High-Pressure Economizer 1 & $\begin{array}{l}\dot{m}_{f g}\left(h_{8}-h_{9}\right)+\dot{m}_{\text {hrsg }}\left(h_{19}-\mathrm{h}_{20}\right)=0 \\
P_{9}=P_{8}-\Delta P_{H P E C 1, \mathrm{fg}} \\
P_{20}=P_{19}-\Delta P_{H P E C 1, \mathrm{~s}} \\
T_{20}=T_{\text {sat }, H P E C 1}-T_{\text {sub,HPEC }} \\
Q_{H P E C 1}=\dot{m}_{\text {hrsg }}\left(\mathrm{h}_{20}-\mathrm{h}_{19}\right) \\
h_{9}=h_{\text {fg@ } @ T_{9}}, \mathrm{~h}_{20}=h_{\text {water } @ P_{20}, T_{20}}\end{array}$ & {$[37,38]$} & $\begin{array}{l}\dot{m}_{f g}, T_{8}, P_{8} \\
\Delta P_{H P E C 1, f g} \\
\Delta P_{H P E C 1, \mathrm{~s}} \\
T_{19}, P_{19} \\
T_{s u b, H P E C 1}\end{array}$ & $\begin{array}{l}Q_{H P E C 1} \\
T_{9}, P_{9} \\
T_{20}, P_{20} \\
\dot{m}_{\text {hrs }}\end{array}$ \\
\hline Deaerator Pressure Evaporator & $\begin{array}{l}\dot{m}_{f g}\left(h_{9}-h_{10}\right)+\dot{m}_{d e}\left(h_{15}-\mathrm{h}_{16}\right)=0 \\
P_{10}=P_{9}-\Delta P_{D P E V, f g} \\
P_{16}=P_{15}-\Delta P_{D P E V, \mathrm{~s}} \\
T_{16}=T_{\text {sat } @ P_{19}} \\
Q_{D P E V}=\dot{m}_{d e}\left(\mathrm{~h}_{16}-\mathrm{h}_{15}\right) \\
h_{10}=h_{\mathrm{fg} @ T_{10}}, \mathrm{~h}_{16}=h_{g, \text { water } @ P_{16}}\end{array}$ & {$[37,38]$} & $\begin{array}{l}\dot{m}_{f g}, T_{9}, P_{9} \\
\Delta P_{D P E V, f g} \\
\Delta P_{D P E V, \mathrm{~s}} \\
T_{15}, P_{15}\end{array}$ & $\begin{array}{l}Q_{D P E V} \\
T_{10}, P_{10} \\
T_{16}, P_{16} \\
\dot{m}_{d e}\end{array}$ \\
\hline Feed Water Preheater & $\begin{array}{l}\dot{m}_{f g}\left(h_{10}-h_{11}\right)+\dot{m}_{f w}\left(h_{12}-\mathrm{h}_{13}\right)=0 \\
P_{11}=P_{10}-\Delta P_{\mathrm{FWPH}, \mathrm{fg}} \\
P_{13}=P_{12}-\Delta P_{\mathrm{FWPH}, \mathrm{s}} \\
T_{13}=T_{\text {sat }, F W P H}-T_{\text {sub }, F W P H} \\
Q_{F W P H}=\dot{m}_{f w}\left(\mathrm{~h}_{13}-\mathrm{h}_{12}\right) \\
h_{11}=h_{\mathrm{fg} @ T_{11}}, \mathrm{~h}_{13}=h_{\text {water } @ P_{13}, T_{13}}\end{array}$ & {$[37,38]$} & $\begin{array}{l}\dot{m}_{f g}, T_{10}, P_{10} \\
\Delta P_{\mathrm{FWPH}, f g} \\
\Delta P_{\mathrm{FWPH}, \mathrm{s}} \\
T_{s u b, F W P H} \\
T_{12}, P_{12}\end{array}$ & $\begin{array}{l}Q_{F W P H} \\
T_{13}, P_{13} \\
T_{11}, P_{11} \\
\dot{m}_{f w}\end{array}$ \\
\hline Deaerator & $\begin{array}{l}\dot{m}_{f w} h_{13}+\dot{m}_{d e} h_{16}-\left(\dot{m}_{f w}+\dot{m}_{d e}\right) h_{14}=0 \\
P_{14}=P_{D E A} \\
T_{14}=T_{\text {sat } @ P_{14}} \\
\mathrm{~h}_{14}=h_{f, \text { water } @ P_{14}} \\
s_{14}=s_{f, \text { water } @ p_{14}}\end{array}$ & {$[37,38]$} & $\begin{array}{l}T_{16}, P_{16} \\
T_{13}, P_{13}\end{array}$ & $\begin{array}{l}T_{14}, P_{14}, s_{14} \\
m_{d e}, \dot{\mathrm{m}}_{f w}\end{array}$ \\
\hline High-Pressure Pump & $\begin{array}{l}W_{H P P}=\dot{m}_{f w}\left(\mathrm{~h}_{18}-\mathrm{h}_{17}\right) \\
\mathrm{P}_{18}=P_{H P P} \\
s_{18 s}=s_{17} \\
h_{18 s}=s_{\text {water } @ p_{18}, s_{18 s}} \\
h_{18}=h_{17}+\frac{h_{18 s}-h_{17}}{\eta_{H P P}} \\
T_{18}=T_{\text {water } @ \mathrm{p}_{18}, h_{18}} \quad[37,38]\end{array}$ & & $\begin{array}{l}T_{17}, P_{17}, s_{17} \\
P_{H P P} \\
\eta_{H P P}\end{array}$ & $\begin{array}{l}T_{18}, P_{18} \\
W_{H P P}\end{array}$ \\
\hline
\end{tabular}


Table 3. Equations, inputs and outputs of the equipment of steam side (Continued)

\begin{tabular}{lllc}
\hline Component & Equations & inputs & outputs \\
\hline Desuperheater & $\dot{m}_{\text {desw }} h_{25}+\dot{m}_{\text {dess }} h_{24}-\dot{m}_{s} h_{26}=0$ & $p_{24}, T_{24}$ & $p_{26}, T_{26}$ \\
& $P_{26}=P_{25}$ & $p_{25}, T_{25}$ & \\
& $T_{26}=T_{\text {sat, DES }}+T_{\text {sup, DES }}$ & $T_{\text {sup, DES }}$ & \\
& $\mathrm{h}_{26}=h_{\text {water } @ T_{26}, P_{26}}$ & & \\
& $h_{27}=h_{26}[37,38]$ & & \\
\hline Valve 1 & {$[37,38]$} & $p_{26}, T_{26}, h_{26}$ & $p_{27}, T_{27}, h_{27}$ \\
& $T_{27}=T_{\text {water } @ p_{27}, h_{27}}$ & $p_{27}$ & \\
\hline Valve 2 & $h_{31}=h_{30}$ & $p_{30}, T_{30}, h_{30}$ & $p_{31}, T_{31}, h_{31}$ \\
& $T_{31}=T_{\text {water } @ p_{31}, h_{31}}[37,38]$ & $p_{31}$ & \\
\hline
\end{tabular}

Table 4. Equations, inputs and outputs of the equipment of MED-TVC

\begin{tabular}{|c|c|c|c|}
\hline Component & Equations & inputs & outputs \\
\hline MED-TVC & 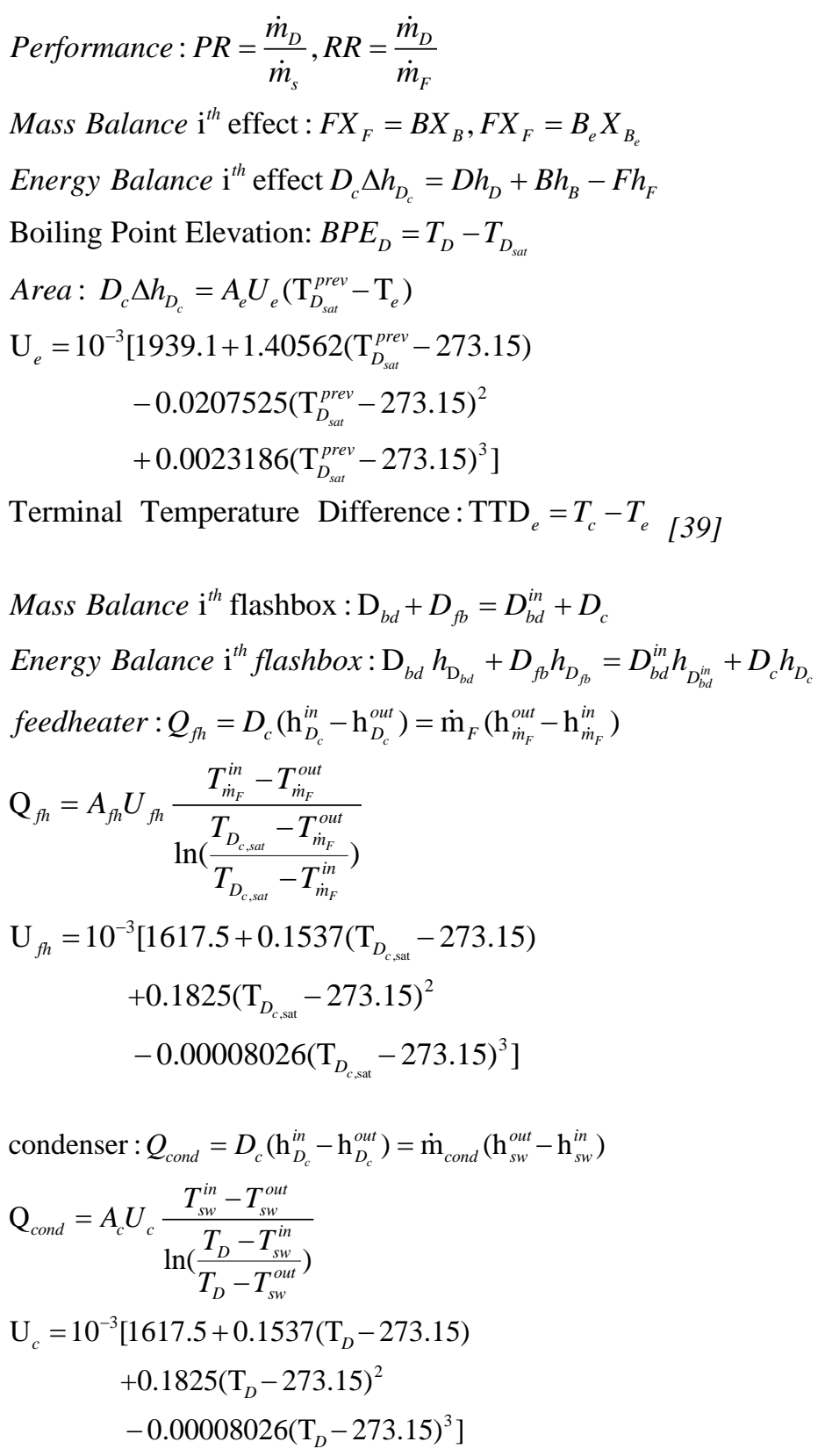 & $\begin{array}{l}n \\
\dot{\mathrm{m}}_{D} \\
T_{s} \\
x_{s w} \\
T T D \\
R R \\
T_{e}(n) \\
\mathrm{T}_{\text {sw,in }}, p_{\text {sw,in }} \\
p_{\text {motive-steam }}\end{array}$ & $\begin{array}{l}S A \\
\dot{m}_{s} \\
\dot{m}_{F} \\
\dot{m}_{s w} \\
\dot{m}_{c w d} \\
x_{B} \\
P R\end{array}$ \\
\hline
\end{tabular}


Table 4. Equations, inputs and outputs of the equipment of MED-TVC (Continued)

\begin{tabular}{|c|c|c|c|}
\hline Component & Equations & inputs & outputs \\
\hline$M E D-T V C$ & $\begin{array}{l}\dot{m}_{D}=\sum_{i=1}^{n} D(i) \\
\dot{m}_{s}=D_{c}(1) \\
\dot{\mathrm{m}}_{F}=F(1) \\
\dot{m}_{B}=B(n) \\
\text { Specific Area }: S A=\frac{\sum A_{e}+\sum A_{f h}+A_{c}}{\dot{m}_{D}} \\
\text { TVC: } \\
E_{r}=\frac{p_{\text {motive-steam }}}{p_{\text {suction }}} \\
C_{r}=\frac{p_{\text {discharge }}}{p_{\text {suction }}} \\
M_{r}=\frac{\dot{m}_{\text {motive-steam }}}{\dot{m}_{\text {suction }}} \\
M_{r}=-1.9342+2.1525 \mathrm{C}_{r}+\frac{113.49}{E_{r}}-0.52 C_{r}^{2} \\
-\frac{14735.96}{E_{r}^{2}}-\frac{31.85 C_{r}}{E_{r}}+0.047 C_{r}{ }^{2} \\
+\frac{900786}{E_{r}^{3}}-\frac{495.6 C_{r}}{E_{r}^{2}}+\frac{10.02 C_{r}^{2}}{E_{r}} \\
\dot{m}_{s}=\frac{\dot{m}_{s, 1^{t}} \text { effect }}{1+M_{r}}\end{array}$ & $\begin{array}{l}n \\
\dot{\mathrm{m}}_{D} \\
T_{s} \\
x_{s w} \\
T T D \\
R R \\
T_{e}(n) \\
\mathrm{T}_{\text {sw,in }}, p_{\text {sw,in }} \\
p_{\text {motive-steam }}\end{array}$ & $\begin{array}{l}S A \\
\dot{m}_{s} \\
\dot{m}_{F} \\
\dot{m}_{s w} \\
\dot{m}_{c w d} \\
x_{B} \\
P R\end{array}$ \\
\hline
\end{tabular}

Table 5. Equations, inputs and outputs of the equipment of $R O$

\begin{tabular}{|c|c|c|c|}
\hline Component & Equations & inputs & outputs \\
\hline RO & $\begin{array}{l}R R=\frac{\dot{m}_{D}}{\dot{m}_{F}} \\
R R=\left.R R\right|_{T=25} \times \frac{J_{w}}{\left.J_{w}\right|_{T=25}} \\
\dot{m}_{F}=\dot{m}_{D}+\dot{m}_{B} \\
\dot{m}_{F}=\dot{m}_{c w d, M E D} \\
\dot{W}_{R O}=\frac{\dot{m}_{F}\left(\mathrm{p}_{\text {Feed }}-\mathrm{p}_{37}\right) \times 100}{\rho \times \eta_{p u m p}} \\
J_{w}=\frac{D_{w} C_{w} V_{w}}{R T e\left[{ }^{0} \mathrm{~K}\right]}\left\{\left(\mathrm{p}_{F}-\mathrm{p}_{D}\right)-\left(\pi_{F}-\pi_{D}\right)\right\} \\
\pi_{i}=\frac{385 \times \text { sal }_{i} \times T_{i}}{0.14507\left(1000-10 \mathrm{sal}_{i}\right)} \\
T: \text { average Temp. of RO } \\
\mathrm{R}: \text { Universal Gas Constant } \\
\text { e:membrane thickness } \\
\mathrm{V}_{w}: \text { water molar volume } \\
\mathrm{C}_{w}: \text { water concentration } \\
D_{w}=\frac{k \times T\left[{ }^{0} \mathrm{~K}\right]}{3 \pi_{F} \mu_{w} d_{s}}\end{array}$ & $\begin{array}{l}\dot{m}_{F} \\
T_{37}, p_{37} \\
p_{\text {Feed }} \\
T \\
\mathrm{R} \\
\mathrm{e}=2 \times 10^{-6}[\mathrm{~m}] \\
\mathrm{V}_{w}=18\left[\mathrm{~m}^{3} / \mathrm{mol}\right] \\
\mathrm{C}_{w}=\rho \\
M W_{w} \\
k: \text { Boltzmann } \\
\eta_{R O-p u m p}\end{array}$ & $\begin{array}{l}\dot{m}_{D}, \dot{m}_{B} \\
R R \\
\dot{W}_{R O} \\
p_{38}, T_{38} \\
p_{39}, T_{39} \\
x_{39}\end{array}$ \\
\hline
\end{tabular}




\begin{tabular}{llll}
\hline Component & Equations & inputs & outputs \\
\hline$R O$ & $\mu_{w}=4.23 \times 10^{-5}+\left[0.157\left(\mathrm{~T}_{F}+64.993\right)^{2}-91.296\right]^{-1}$ & $\dot{m}_{F}$ & $\dot{m}_{D}, \dot{m}_{B}$ \\
& $d_{s}=0.076 M W_{w}$ & $T_{37}, p_{37}$ & $R R$ \\
& $d_{s}:$ Stocks diameter & $p_{\text {Feed }}$ & $\dot{W}_{R O}$ \\
& $M W:$ Molcular Weight & $T$ & $p_{38}, T_{38}$ \\
& & $\mathrm{R}$ & $p_{39}, T_{39}$ \\
& $s a l_{B}=\frac{s a l_{F}}{1-R R} \quad[46]$ & $\mathrm{C}_{w}=\rho$ & $x_{39}$ \\
& $h_{39}=\frac{h_{37}-R R \times h_{38}}{1-R R}$ & $k W_{w}$ & \\
\hline
\end{tabular}

Table 6. Fuel and Product exergy streams of the equipment

\begin{tabular}{lll}
\hline Component & $\dot{E} x_{\mathrm{F}}$ & $\dot{E} x_{\mathrm{P}}$ \\
\hline Air Compressor & $W_{A C}$ & $\dot{E} x_{2}-\dot{E} x_{1}$ \\
Combustion Chamber & $\dot{E} x_{2}+\dot{E} x_{3}$ & $\dot{E} x_{4}$ \\
Gas Turbine & $\dot{E} x_{4}-\dot{E} x_{5}$ & $\dot{W_{G T}}$ \\
High-Pressure Super heater & $\dot{E} x_{5}-\dot{E} x_{6}$ & $\dot{E} x_{23}-\dot{E} x_{22}$ \\
High-Pressure Evaporator & $\dot{E} x_{6}-\dot{E} x_{7}$ & $\dot{E} x_{22}-\dot{E} x_{21}$ \\
High-Pressure Economizer 2 & $\dot{E} x_{7}-\dot{E} x_{8}$ & $\dot{E} x_{21}-\dot{E} x_{20}$ \\
High-Pressure Economizer 1 & $\dot{E} x_{8}-\dot{E} x_{9}$ & $\dot{E} x_{20}-\dot{E} x_{19}$ \\
Deaerator Pressure Evaporator & $\dot{E} x_{9}-\dot{E} x_{10}$ & $\dot{E} x_{16}-\dot{E} x_{15}$ \\
Feed Water Preheater & $\dot{E} x_{10}-\dot{E} x_{11}$ & $\dot{E} x_{13}-\dot{E} x_{12}$ \\
Deaerator & $\dot{E} x_{13}+\dot{E} x_{16}$ & $\dot{E} x_{14}$ \\
HRSG Pack & $\dot{E} x_{5}-\dot{E} x_{11}$ & $\dot{E} x_{23}+\dot{E} x_{25}-\dot{E} x_{12}$ \\
High-Pressure Pump & $\dot{W}_{H P P}$ & $\dot{E} x_{18}-\dot{E} x_{17}$ \\
De-super heater & $\dot{E} x_{24}+\dot{E} x_{25}$ & $\dot{E} x_{26}$ \\
Process Heat Exchanger & $\dot{E} x_{28}-\dot{E} x_{29}$ & $\dot{E} x_{36}-\dot{E} x_{35}$ \\
Valve 1 & $\dot{E} x_{26}$ & $\dot{E} x_{27}$ \\
Valve 2 & $\dot{E} x_{30}$ & $\dot{E} x_{31}$ \\
MED-TVC & $\dot{E} x_{27}+\dot{E} x_{32}$ & $\dot{E} x_{34}+\dot{E} x_{30}+\dot{E} x_{37}+\dot{E} x_{30}$ \\
RO & $\dot{E} x_{37}+\dot{W}_{R O-p u m p}$ & $\dot{E} x_{38}$ \\
\hline & & \\
\hline & &
\end{tabular}


Table 7. Purchase Equipment Cost of the equipment in [\$]

\begin{tabular}{|c|c|}
\hline Component & equation \\
\hline Air Compressor & $44.71 m_{a} \cdot r_{p, A C} \cdot \ln \left(r_{p, A C}\right) \cdot \frac{1}{0.95-\eta_{A C}}$ \\
\hline Combustion Chamber & $\frac{28.98 \mathrm{~m}_{a}}{0.995-\frac{p_{\text {out }}}{p_{\text {in }}}} \cdot\left(1+\mathrm{e}^{\left(0.015\left(\mathrm{~T}_{\text {out }}-1540\right)\right)}\right)$ [38] \\
\hline Gas Turbine & $479.34 \frac{\mathrm{m}_{f g}}{0.93-\eta_{G T}} \cdot \ln \left(\mathrm{r}_{p, G T}\right) \cdot\left(1+\mathrm{e}^{\left(0.036 * T_{i n}-54.4\right)}\right)[41]$ \\
\hline HRSG & $6570\left[\left(\frac{Q_{E C}}{\Delta T_{E C}}\right)^{0.8}+\left(\frac{Q_{E V}}{\Delta T_{E V}}\right)^{0.8}+\left(\frac{Q_{S H}}{\Delta T_{S H}}\right)^{0.8}\right]+21276 \mathrm{~m}_{w}+1184.4 m_{f g}^{1.2}[41]$ \\
\hline Deaerator & $145315\left(\dot{\mathrm{m}}_{\text {water }}\right)^{0.7}$ \\
\hline Pump & $3540 W_{\text {Pump }}^{0.71}[42]$ \\
\hline Valve & $8.07 \times 0.989 \times \dot{m} \times\left(\frac{T_{i}}{p}\right)^{0.05} \times P_{e}^{-0.75}[43]$ \\
\hline Desuperheater & $1060 \times \frac{\dot{m}}{\rho}[43]$ \\
\hline MED & $\begin{array}{l}\sum P E C_{\text {effects }}+\sum P E C_{\text {feed-heaters }}+\sum P E C_{\text {flash-boxes }}+P E C_{\text {condenser }} \\
P E C_{H X}=12000\left(\frac{\text { Area }}{100}\right)^{0.6}\end{array}$ \\
\hline TVC & $2 \times 8.07 \times 0.989 \times \dot{m} \times\left(\frac{T_{i}}{P_{i}}\right)^{0.05} \times P_{e}^{-0.75}$ \\
\hline RO & $\begin{array}{l}P E C_{\text {membrane }}+P E C_{\text {pretreat }}+P E C_{R O-\text { pump }}+P E C_{R O-\text { valve }} \\
P E C_{\text {membrane }}=N O \text { membranes }_{\text {menem }} \times P E C_{\text {one-membrane }} \\
P E C_{\text {one-membrane }}=7846 \\
P E C_{\text {pretreat }}=996 \times \xi_{1}\left(\frac{\dot{m}_{R O-\text { feed }}}{\rho} \times 24 \times 3600\right)^{0.8} \\
\xi_{1}=1.399: \text { inflation factor } \\
P E C_{R O-\text { pump }}=393000 \xi_{1}+701.19 \times 14.5 \times P_{R O-\text { feed }} \\
P E C_{R O-\text { valve }}=8.07 \times 0.989 \times \dot{m} \times\left(\frac{T_{i}}{P_{i}}\right)^{0.05} \times P_{e}^{-0.75}\end{array}$ \\
\hline
\end{tabular}

Using the purchased equipment cost of the components, the cost rate of the equipment can be obtained according to the equation (12) [37].

$$
\dot{Z}_{k}=\frac{\Phi_{k} \times P E C_{k} \times C R F}{3600 \times N}
$$

Which $\emptyset_{k}$ is the maintenance factor and it is the representative of the effect of the maintenance costs. The value of this factor has been proposed to be considered $1.06[36,37]$.

$\mathrm{N}$ is the annual operating hours of the system and it can be considered hours [36, 37].

CRF is the capital recovery factor which can be determined using equation (13) [36]:

$C R F=\frac{i \times(1+i)^{n y}}{(1+i)^{n y}-1}$
Which $i$ is interest rate and ny is the working years of the system and it is usually considered about 25 years for power production systems [36, 37].

In order to find the values of cost per exergy unit of all streams, the exergoeconomic balance for each component should be written down like equation (14), (15) [36]. As a result, a system of equations will be formed, and it needs to be solved. A matrix solution has been performed to solve this system.

After determining the cost per exergy unit of all the streams, multiplying this cost by their exergy rate, cost rate of the streams will be obtained as shown in equation (16).

$\dot{C}_{P, k}=\dot{C}_{F, k}-\dot{C}_{L, k}+\dot{Z}_{k}$

$\sum_{e} \dot{C}_{e, k}+\dot{C}_{w, k}=\dot{C}_{q, k}-\sum_{i} \dot{C}_{i, k}+\dot{Z}_{k}$

$\dot{C}_{i}=c_{i} \cdot \dot{E} x_{i}$ 
Which $\dot{C}_{P}$ is the product stream's cost rate of the equipment, $\dot{C}_{F}$ is the cost rate of fuel stream of the equipment and $\dot{Z}$ is cost rate associated with each component's capital cost rate and operating and maintenance cost.

The exergy destruction's cost rate of the equipment can be determined using equation (17) [36]. This parameter has a significant part in further discussions and indicates importance of each component's exergy destruction economically.

$$
\dot{C}_{D, k}=c_{F, k} \cdot \dot{E} x_{D, k}
$$

The exergoeconomic factor for each component can be calculated as follow [36]. The exergoeconomic factor can be evaluated by equation (18), and it indicates the relation between capital cost rate and cost of exergy destruction rate. This factor is a useful tool to recognize which component can be improved by lowering its cost. Furthermore, if the exergoeconomic factor is too low, it means exergy destruction of the component costs too much, and this component needs to work more efficient thermodynamically.

$f_{k}=\frac{\dot{Z}_{k}}{\dot{Z}_{k}+c_{f, k} \dot{E} x_{D, k}}$

The relative cost difference of the equipment indicates the fraction of the product's cost to that of fuel for each component, and it can be calculated using equation (19). The components with the highest relative cost difference are good targets to be investigated in order to diminish the extra costs they take [36].

$r_{k}=\frac{c_{\mathrm{P}, k}-c_{F, k}}{c_{F, k}}=\frac{1-\varepsilon_{k}}{\varepsilon_{k}}+\frac{\dot{Z}_{k}}{c_{f, k} \dot{E} x_{\mathrm{P}, k}}$

\subsection{Exergoenvironmental Analysis}

The exergoenvironmental analysis includes three steps. First, the exergy analysis is performed for each stream and component of the system. In the second step, the environmental impacts of each component in the processes of manufacturing, operating and disposal is determined, and in the third step the exergoenvironmental balance is implemented in order to calculate the environmental impact of each stream of the system. The exergoenvironmental balance for each component can be written as follow [40].

$$
\begin{aligned}
& \dot{B}_{P, k}=\dot{B}_{F, k}-\dot{B}_{L, k}+\dot{Y}_{k} \\
& \sum_{e} \dot{B}_{e, k}+\dot{B}_{w, k}=\dot{B}_{q, k}-\sum_{i} \dot{B}_{i, k}+\dot{Y}_{k} \\
& \dot{B}_{i}=b_{i} \cdot \dot{E} x_{i}
\end{aligned}
$$

The exergy destruction's environmental impact rate of the equipment can be found as equation (23) [40].

$$
\dot{B}_{D, k}=b_{F, k} \cdot \dot{E} x_{D, k}
$$

The exergoenvironmental factor for each component can be obtained as equation (24) [40].

$$
f b_{k}=\frac{\dot{Y_{k}}}{\dot{Y_{k}}+b_{f, k} \dot{E} x_{D, k}}
$$

The relative environmental impact difference of the equipment is given as follow [40].

$$
r b_{k}=\frac{b_{\mathrm{P}, k}-b_{F, k}}{b_{F, k}}=\frac{1-\varepsilon_{k}}{\varepsilon_{k}}+\frac{\dot{Y_{k}}}{b_{f, k} \dot{E} x_{\mathrm{P}, k}}
$$

Environmental impact of the equipment can be obtained by multiplying the weight by the environmental impact per mass unit of the components as shown as equation (26) [40]. $y_{k}=w_{k} \times b m_{k}$

$y$ is environmental impact of the component in pts, $w$ is weight of the component in tons and $\mathrm{bm}$ is the environmental impact per mass unit of the component in pts/ton which is a function of the component's material and its process of

\begin{tabular}{|c|c|c|}
\hline Component & material composition & $b m_{k}(\mathrm{pts} / \mathrm{ton})$ \\
\hline $\begin{array}{l}\text { Air } \\
\text { Compressor }\end{array}$ & $\begin{array}{l}\text { Steel } 33.33 \% \text { steel low alloy } \\
44.5 \% \text { cast iron } 22.22\end{array}$ & 71.7 \\
\hline $\begin{array}{l}\text { Combustion } \\
\text { Chamber }\end{array}$ & $\begin{array}{l}\text { Steel } 33.34 \% \text { steel high alloy } \\
66.66 \%\end{array}$ & 585 \\
\hline Gas Turbine & Steel $25 \%$ steel high alloy $75 \%$ & 645.7 \\
\hline Superheater & Steel $26 \%$ steel high alloy $74 \%$ & 638 \\
\hline Evaporator & Steel $100 \%$ & 28 \\
\hline Economizer & Steel $100 \%$ & 28 \\
\hline Deaerator & Steel $100 \%$ & 28 \\
\hline Pump & Steel $35 \%$ cast iron $65 \%$ & 132.8 \\
\hline TVC & Steel $100 \%$ & 28 \\
\hline
\end{tabular}
manufacturing. It can be derived from Eco-indicator 99 knowing the material composition of each component [41]. Table 8 shows the environmental impact per mass unit of the equipment.

Table 8. Environmental impact per mass unit of the component in pts/ton [40]

The weight functions of the components are gathered in the table 9 .

The weight function of TVC is derived and proposed in this paper using technical data of TVCs in different nominal sizes manufactured by KADANT Corporation.

Environmental impact rate of $\mathrm{RO}$ in $\mathrm{mpts} / \mathrm{h} . \mathrm{m}^{3}$ of distillate produced can be calculated using equation (27) [42].

$\dot{Y_{R O}}=0.0195 \times \frac{\rho \times \dot{W}_{R O}}{3600 \times \dot{m}_{R O-\text { distillate }}}+0.00595$

Environmental impact rate of MED in mpts $/ h . \mathrm{m}^{3}$ distillate can be considered $\dot{Y}_{M E D}=1.277$. [42]

\section{Result and Discussion}

As stated, the studied system is the combined cycle power plant located in Qeshm Island which involves power, heat and water production units. This multi generation system utilizes MED-TVC type to produce distillate. Evaluation of integrating this scheme with a $\mathrm{RO}$ desalination unit has been carried out. In a power plant, there is a combination of points that can be used as a source of energy in other heating systems, such as hot water sprinklers. These points include the heat dissipated by the outlet of the power plant chimney, the steam outlet from the LP line, and the entrance to the condenser, the discharge line of the LP and HP. Regarding the use of waste heat from the chimney, which is done by adding an auxiliary cycle to the end of the boiler, it should be noted that this mode does not have the ability to supply the pressure required for the commissioning of the thermocouple. However, it is suitable for use in other types of water Thermal desalination unit without thermal 
vapor compressor. In the case of using the steam outlet from the LP line and using the first stage of the desalination system instead of the condenser, it should be noted that this steam not only does not have the ability to supply the pressure required for the commissioning of the thermocouple compressor, but because of its low temperature, It is also not used in other types of thermal desalination. Considering withdrawal of the HP line due to the high steam pressure at this stage and being above the pressure range of the thermocouple compressors, the idea of using steam turbine to decrease the high pressure can be discussed as an option.

The project for the production of electricity, and water in Qeshm, with the aim of saving fossil fuels and increasing the efficiency of gas turbine power plants, was exploited with a capacity of 50 megawatts of electricity and 18 thousand cubic meters of Freshwater. The thermodynamic properties of the cycle including mass flow rate, temperature and pressure are presented in the table 10. The mentioned thermodynamic data and also the exergoeconomical and exergoenvironmental parameters related to the streams calculated by programming in MATLAB software, extracted and gathered in this table.

The stream No.4, which is the output stream of the combustion chamber, has the highest exergy rate among all cyclic flows. This flow is about 90 megawatts of exergy. In addition, the flow of the outlet from the combustion chamber has the highest cost rate in the material streams. This stream costs $\$ 3,548.5$ per hour per cycle. It also has the highest altitudinal rate throughout the entire cycle. In this process, the rate of environmental impacts is about 1471 mpts per second. The reason for the high rate of exergy in this flow is the high temperature, and pressure of the exhaust stream from the combustion chamber. Also due to the use of fossil fuels in the combustion chamber, the cost, and intensity of contamination of this stream has determined quite high. Nevertheless, after the flow of the outlet from the combustion chamber, the fuel flow into it has the highest exergy rate. It has an exergy content of about 73 megawatts. The cost of the fuel flow is about $\$ 1703$ per hour, and its environmental impact rate is about 753 mpts per hour.

The process of evaluating the Data Mining models name actual data is called Validation. The point is very important before validating data mining models in a protected environment, confirming these models by understanding their quality, and features. Many methods have been proposed to evaluate the quality, and characteristics of the data-mining model. Different criteria of statistical validity are used to determine whether a data problem is involved or data mining models. The data is broken down into training, and experimental sets to examine the accuracy of predictions. In order to determine if the patterns found for a specific business purpose are effective, commercial experts are required to examine the results of the data-mining model. The validation of main parameters of the cycle that has been modeled in the MATLAB and Thermoflex software has been presented in the table 11. It is noted that the results extracted from Thermoflex simulation software conform to the technical data gathered from the Qeshm combined cycle power plant.

Table 10. Thermodynamic, exergoeconomic and exergoenvironmental data of all material streams

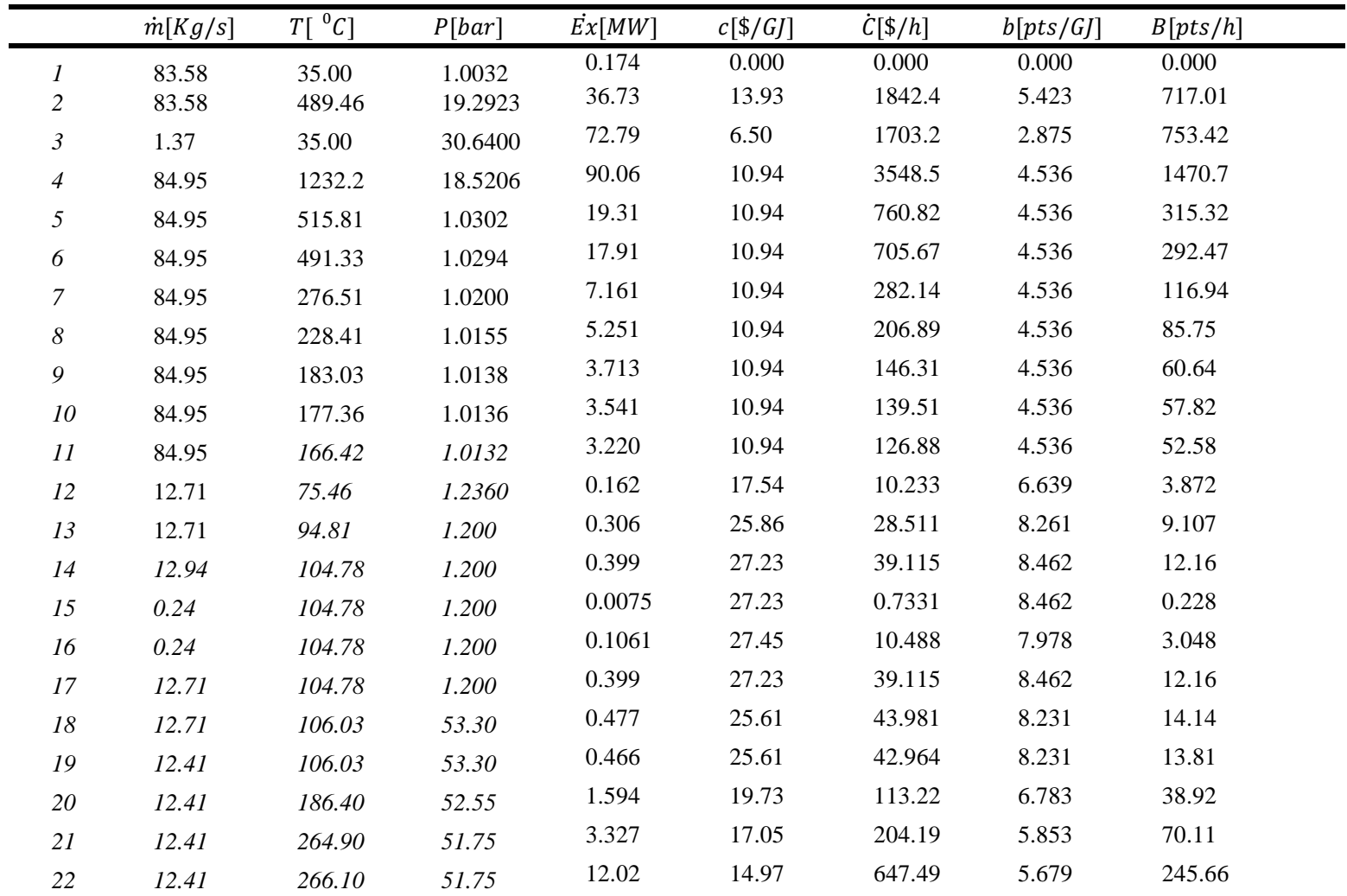


Table 10. Thermodynamic, exergoeconomic and exergoenvironmental data of all material streams(Continued)

\begin{tabular}{|c|c|c|c|c|c|c|c|c|}
\hline & $\dot{m}[\mathrm{Kg} / \mathrm{s}]$ & $T\left[{ }^{0} C\right]$ & $P[$ bar $]$ & $\dot{E x}[M W]$ & $c[\$ / G J]$ & $\dot{C}[\$ / h]$ & $b[p t s / G J]$ & $B[p t s / h]$ \\
\hline 23 & 12.41 & 317.50 & 50.00 & 13.01 & 15.12 & 708.15 & 5.735 & 268.59 \\
\hline 24 & 5.66 & 317.50 & 50.00 & 5.934 & 15.12 & 323.01 & 5.735 & 122.51 \\
\hline 25 & 0.29 & 106.03 & 53.30 & 0.011 & 25.61 & 1.017 & 8.231 & 0.327 \\
\hline 26 & 5.95 & 278.90 & 50.00 & 5.900 & 15.31 & 325.17 & 5.783 & 122.84 \\
\hline 27 & 5.95 & 217.11 & 12.90 & 4.882 & 18.50 & 325.17 & 6.989 & 122.84 \\
\hline 28 & 6.75 & 315.00 & 50.00 & 7.052 & 15.12 & 383.85 & 5.735 & 145.59 \\
\hline 29 & 6.75 & 82.22 & 1.236 & 0.120 & 15.12 & 5.981 & 5.735 & 2.269 \\
\hline 30 & 5.95 & 67.50 & 16.00 & 0.064 & 18.50 & 4.244 & 6.989 & 1.603 \\
\hline 31 & 5.95 & 67.79 & 1.236 & 0.056 & 21.25 & 4.251 & 8.014 & 1.603 \\
\hline 32 & 316.42 & 35.00 & 1.0132 & 0.000 & 0.000 & 0.000 & 0.000 & 0.000 \\
\hline 33 & 123.19 & 48.71 & 1.0132 & 1.498 & 0.000 & 0.000 & 0.000 & 0.000 \\
\hline 34 & 51.72 & 48.15 & 4.500 & 0.206 & 471.2 & 349.83 & 487.1 & 361.64 \\
\hline 35 & 141.48 & 35.00 & 2.000 & 0.367 & 0.000 & 0.000 & 0.000 & 0.000 \\
\hline 36 & 141.48 & 65.00 & 1.400 & 1.170 & 89.75 & 378.18 & 34.01 & 143.32 \\
\hline 37 & 141.51 & 45.00 & 1.0132 & 0.089 & 0.000 & 0.000 & 0.000 & 0.000 \\
\hline 38 & 70.87 & 45.00 & 1.0132 & 0.224 & 161.12 & 129.94 & 38.98 & 31.437 \\
\hline 39 & 70.65 & 46.45 & 1.0132 & 2.774 & 0.000 & 0.000 & 0.000 & 0.000 \\
\hline
\end{tabular}

Table 11. Comparison of main parameters of thermodynamic modeling in Thermoflex with those of first law analysis programed in MATLAB concerned with the streams

\begin{tabular}{|c|c|c|c|c|c|c|c|c|c|}
\hline & & $\dot{m}[\mathrm{Kg} / \mathrm{s}]$ & & & $T\left[{ }^{0} \mathrm{C}\right]$ & & & $P[$ bar $]$ & \\
\hline & MATLAB & Thermoflex & Error [\%] & MATLAB & Thermoflex & Error $[\%]$ & MATLAB & Thermoflex & Error [\%] \\
\hline 1 & 83.58 & 83.53 & 0.06 & 35.00 & 35.00 & 0.00 & 1.0032 & 1.003 & 0.02 \\
\hline 2 & 83.58 & 83.53 & 0.06 & 489.46 & 488.6 & 0.18 & 19.2923 & 19.5 & 1.07 \\
\hline 3 & 1.37 & 1.419 & 3.45 & 35.00 & 35.00 & 0.00 & 30.6400 & 30.64 & 0.00 \\
\hline 4 & 84.95 & 84.94 & 0.01 & 1232.2 & 1232.2 & 0.00 & 18.5206 & 18.72 & 1.07 \\
\hline 5 & 84.95 & 84.94 & 0.01 & 515.81 & 515 & 0.16 & 1.0302 & 1.0302 & 0.00 \\
\hline 6 & 84.95 & 84.94 & 0.01 & 491.33 & 491.4 & 0.01 & 1.0294 & 1.0294 & 0.00 \\
\hline 7 & 84.95 & 84.94 & 0.01 & 276.51 & 279.1 & 0.93 & 1.0200 & 1.02 & 0.00 \\
\hline 8 & 84.95 & 84.94 & 0.01 & 228.41 & 230 & 0.69 & 1.0155 & 1.0155 & 0.00 \\
\hline 9 & 84.95 & 84.94 & 0.01 & 183.03 & 183.3 & 0.15 & 1.0138 & 1.0138 & 0.00 \\
\hline 10 & 84.95 & 84.94 & 0.01 & 177.36 & 177.4 & 0.02 & 1.0136 & 1.0136 & 0.00 \\
\hline 11 & 84.95 & 84.94 & 0.01 & 166.42 & 166.1 & 0.19 & 1.0132 & 1.0132 & 0.00 \\
\hline 12 & 12.71 & 12.76 & 0.39 & 75.46 & 75.59 & 0.17 & 1.2360 & 1.236 & 0.00 \\
\hline 13 & 12.71 & 12.76 & 0.39 & 94.81 & 94.81 & 0.00 & 1.200 & 1.2 & 0.00 \\
\hline 14 & 12.94 & 13.00 & 0.46 & 104.78 & 104.8 & 0.02 & 1.200 & 1.2 & 0.00 \\
\hline 15 & 0.24 & 0.24 & 0.00 & 104.78 & 104.8 & 0.02 & 1.200 & 1.2 & 0.00 \\
\hline 16 & 0.24 & 0.24 & 0.00 & 104.78 & 104.8 & 0.02 & 1.200 & 1.2 & 0.00 \\
\hline 17 & 12.71 & 12.76 & 0.39 & 104.78 & 104.8 & 0.02 & 1.200 & 1.2 & 0.00 \\
\hline 18 & 12.71 & 12.76 & 0.39 & 106.03 & 106.1 & 0.07 & 53.30 & 53.3 & 0.00 \\
\hline 19 & 12.41 & 12.46 & 0.40 & 106.03 & 106.1 & 0.07 & 53.30 & 53.3 & 0.00 \\
\hline 20 & 12.41 & 12.46 & 0.40 & 186.40 & 186.4 & 0.00 & 52.55 & 52.55 & 0.00 \\
\hline 21 & 12.41 & 12.46 & 0.40 & 264.90 & 264.9 & 0.00 & 51.75 & 51.75 & 0.00 \\
\hline 22 & 12.41 & 12.46 & 0.40 & 266.10 & 266.1 & 0.00 & 51.75 & 51.75 & 0.00 \\
\hline 23 & 12.41 & 12.46 & 0.40 & 317.50 & 317.5 & 0.00 & 50.00 & 50.00 & 0.00 \\
\hline 24 & 5.66 & 5.668 & 0.14 & 317.50 & 317.5 & 0.00 & 50.00 & 50.00 & 0.00 \\
\hline 25 & 0.29 & 0.299 & 3.01 & 106.03 & 106.1 & 0.07 & 53.30 & 53.3 & 0.00 \\
\hline 26 & 5.95 & 5.967 & 0.28 & 278.90 & 278.9 & 0.00 & 50.00 & 50.00 & 0.00 \\
\hline 27 & 5.95 & 5.967 & 0.28 & 217.11 & 217.2 & 0.04 & 12.90 & 12.9 & 0.00 \\
\hline 28 & 6.75 & 6.788 & 0.56 & 315.00 & 317.5 & 0.79 & 50.00 & 50.00 & 0.00 \\
\hline 29 & 6.75 & 6.788 & 0.56 & 82.22 & 82.22 & 0.00 & 1.236 & 1.236 & 0.00 \\
\hline
\end{tabular}


Table 11. Comparison of main parameters of thermodynamic modeling in Thermoflex with those of first law analysis programed in MATLAB concerned with the streams(Continued)

\begin{tabular}{|c|c|c|c|c|c|c|c|c|c|}
\hline & \multicolumn{3}{|c|}{$\dot{m}[\mathrm{Kg} / \mathrm{s}]$} & \multicolumn{3}{|c|}{$T\left[{ }^{0} \mathrm{C}\right]$} & \multicolumn{3}{|c|}{$P[$ bar $]$} \\
\hline & MATLAB & Thermoflex & Error [\%] & $M A T L A B$ & Thermoflex & Error $[\%]$ & $M A T L A B$ & Thermoflex & Error [\%] \\
\hline 30 & 5.95 & 5.967 & 0.28 & 67.50 & 67.74 & 0.35 & 16.00 & 16.00 & 0.00 \\
\hline 31 & 5.95 & 5.967 & 0.28 & 67.79 & 68.02 & 0.34 & 1.236 & 1.236 & 0.00 \\
\hline 32 & 316.42 & 343.4 & 7.86 & 35.00 & 35.00 & 0.00 & 1.0132 & 1.0132 & 0.00 \\
\hline 33 & 123.19 & 123.1 & 0.07 & 48.71 & 47.68 & 2.16 & 1.0132 & 1.014 & 0.08 \\
\hline 34 & 51.72 & 51.72 & 0.00 & 48.15 & 47.14 & 2.14 & 4.500 & 4.50 & 0.00 \\
\hline 35 & 141.48 & 141.61 & 0.09 & 35.00 & 35.00 & 0.00 & 2.000 & 2.00 & 0.00 \\
\hline 36 & 141.48 & 141.61 & 0.09 & 65.00 & 65.00 & 0.00 & 1.400 & 1.40 & 0.00 \\
\hline 37 & 141.51 & 141.51 & 0.00 & 45.00 & 45.06 & 0.13 & 1.0132 & 1.014 & 0.08 \\
\hline 38 & 70.87 & 70.64 & 0.33 & 45.00 & 48.74 & 7.67 & 1.0132 & 1.013 & 0.02 \\
\hline 39 & 70.65 & 70.87 & 0.31 & 46.45 & 46.91 & 0.98 & 1.0132 & 1.013 & 0.02 \\
\hline
\end{tabular}

According to Table 11, the simulation error is acceptable in both MATLAB and Thermoflex software and these results can be used as the basis for calculations in the next steps. The growing demand for electric power supplies makes the construction of new power plants inevitable. Considering the major share of thermal power plants, including gas power plants, in the country's power generation, construction of these power plants is of particular importance. Since the cost of building power plants is quite high, it is vital to increase the productivity of existing power plants, and next, the construction of a new power plant should be considered. One of the most important indicators in the electric power industry is the efficiency of power plants, which is usually the concern of the power industry in the world, so that it can meet the needs of power consumption by raising it as much as possible, and make the waste of energy so logical. In this study, using the concept of synchronous production, the efficiency of a gas cycle has increased. In this simultaneous production process, in addition to producing power in gas turbines, it employs gas from the gas turbine, and steam is produced, and using this steam, Freshwater is produced in other units. Table 12 shows the amount of power production, power consumption, and heat exchanged in different sectors as well as the performance parameters related to the water desalination unit.

Table 12. Comparison of main parameters of thermodynamic modeling in Thermoflex with those of first law analysis programed in MATLAB concerned with the components

\begin{tabular}{llll}
\hline & MATLAB & Thermoflex & Error [\%] \\
\hline $\mathrm{W}_{\mathrm{GT} \mathrm{Pack}}[\mathrm{MW}]$ & 25.67 & 25.36 & 1.222397 \\
$\mathrm{~W}_{\mathrm{AC}}[\mathrm{MW}]$ & 41.94 & 39.63 & 5.828917 \\
$\mathrm{~W}_{\mathrm{GT}}[\mathrm{MW}]$ & 67.61 & 65.30 & 3.537519 \\
$\mathrm{Q}_{\mathrm{HPSH}}[\mathrm{MW}]$ & 2.31 & 2.32 & 0.431034 \\
$\mathrm{Q}_{\mathrm{HPEV}}[\mathrm{MW}]$ & 20.27 & 20.33 & 0.29513 \\
$\mathrm{Q}_{\text {HPEC } 2}[\mathrm{MW}]$ & 4.54 & 4.56 & 0.438596 \\
$\mathrm{Q}_{\mathrm{HPEC} 1}[\mathrm{MW}]$ & 4.28 & 4.29 & 0.2331 \\
$\mathrm{Q}_{\mathrm{DPEV}}[\mathrm{MW}]$ & 0.53 & 0.537 & 1.303538 \\
$\mathrm{Q}_{\mathrm{FWPH}}[\mathrm{MW}]$ & 1.03 & 1.029 & 0.097182 \\
$\mathrm{~W}_{\mathrm{HPP}}[\mathrm{KW}]$ & 115.76 & 119.6 & 3.210702 \\
$\mathrm{PR}_{\mathrm{MED}-\mathrm{TVC}}$ & 8.68 & 8.668 & 0.13844 \\
$\mathrm{RR}_{\mathrm{RO}}$ & 0.5008 & 0.5006 & 0.039952 \\
\hline
\end{tabular}

The power generated by the $25.7 \mathrm{MW}$ gas turbine package is achieved through MATLAB coding. This parameter is calculated at $25.4 \mathrm{MW}$ through the Thermoflex software.

The compressor consumes $62 \%$ of the power output by the gas turbine. The amount of heat exchanged in each of the heat exchangers through MATLAB coding and Thermoflex simulation is shown in Table 12. Also, the amount of error between coding and simulation has been reported. The performance ratio of each desalination unit is another important parameter. This amount for MEDTVC is about 8.7. This value represents the proportion of fresh water produced to steam demand by this unit. The value of this parameter for RO desalination unit is 0.5 .

The increase in energy demand in the 21 st century has been accompanied by problems such as environmental pollution, lack of natural resources and the limitation of space for the construction of fossil fuel cites. On the other hand, technological progress in the world has grown dramatically in demand for energy, especially electricity. In this regard, it is essential to find ways to produce more energy efficiently, eliminating the irreversible factors in energy consumer systems, and optimizing energy consumption by exergy analysis. The exergy destruction rate in each component has been presented in figure 5 .

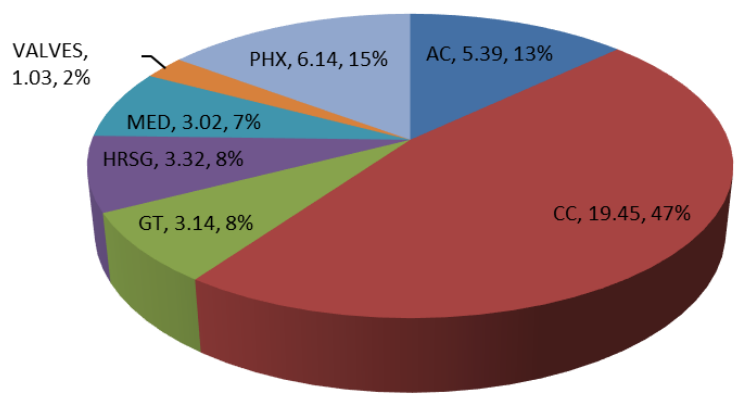

Figure 5. Exergy destruction distribution of the equipment in $M W$ and percent

According to Fig. 5, the highest rate of exergy degradation is related to the combustion chamber, which accounts for about $45.5 \%$ of the total exergy destruction of the cycle. The combustion chamber has about 19.5 megawatts of exergy destruction. The process heat 
exchanger is the next component which has the highest rate of exergy destruction. This component has about 6.14 megawatts of exergy destruction, which is about $15 \%$ of the total exergy destruction of the cycle. The exergy destruction of the air compressor is $13 \%$, and the gas turbine has $8 \%$ of total exergy destruction. The MED unit also has a $7 \%$ destruction of the exergy cycle.

The validation of the desalination units main parameters are presented in the table 13 and 14. The modeling has been done in the Thermoflex and MATLAB software. The results show that the errors are acceptable.

Table 13. Validation of MED-TVC results through comparison of MATLAB and Thermoflex modeling

\begin{tabular}{llll}
\hline & MATLAB & Thermoflex & Error [\%] \\
\hline No. of effects & 5 & 5 & 0.000 \\
GOR & 8.68 & 8.668 & 0.138 \\
$\mathrm{SA}$ & 333.67 & 351.56 & 5.088 \\
$\dot{m}_{\text {steam }}(\mathrm{kg} / \mathrm{s})$ & 5.9551 & 5.967 & 0.199 \\
$\dot{m}_{\text {disillate }}(\mathrm{kg} / \mathrm{s})$ & 51.72 & 51.72 & 0.000 \\
\hline
\end{tabular}

In the MED desalination unit, $5.96 \mathrm{~kg} / \mathrm{s}$ steam has been consumed to produce $51.7 \mathrm{~kg} / \mathrm{s}$ Freshwater.

Table 14. Validation of $R O$ results through comparison of MATLAB and Al-Zahrani and Zhou

\begin{tabular}{llll}
\hline & MATLAB & Al-Zahrani [46] & $\begin{array}{l}\text { Zhou } \\
{[51]}\end{array}$ \\
\hline Feed Pressure(bar) & 50 & 50 & 50 \\
Feed Salinity (\%) & 3 & 3 & 3 \\
RR & 0.5008 & 0.51 & 0.481 \\
\hline
\end{tabular}

The ever-increasing demand for water and services resulting from population growth, and rising standards of living, and health and on the other hand, the limitation of water resources and droughts and climate change are the view of engineers and water experts from unconventional waters (sewage, wastewater, and saline water). Also, the disposal of industrial, and urban wastewater, and the penetration of existing contaminations into surface water, and groundwater resources is a major concern in many countries, including Iran. Sewage treatment and its application in various uses negatively affect the release of wastewater to the environment, and the health of human societies. Based on that, in this paper, the methodology of economic and environmental assessment of sweet water production from Persian Gulf and the economic and environmental assessment of this project has been addressed. The exergoenvironmental and exergoeconomic analysis results are presented in table 15 . Moreover, the exergetic efficiencies of the equipment have been shown in this table and represent the fraction of product to fuel exergy of components. Thus, this parameter can be used to assess the efficiency of the equipment exergetically which is more appropriate criteria than thermal efficiency, because the quality of energy has been considered in calculating exergetic efficiency, rather than only its quantity.

The highest rate of purchase is related to the air compressor, and then desalination unit also have a high cost rate. The cost of exergy destruction in the combustion chamber has the highest value, and it costs $\$ 630$ per hour. The cost of exergy destruction in the combustion chamber is approximately 3 times the air compressor, and 5 times the gas turbine. Similarly, the rate of environmental impact associated with exergy destruction in the combustion chamber has the highest amount.

The exergoeconomic factor indicates the relation between the investment cost rate and the cost of exergy destruction rate. So that, the larger exergoeconomic factor indicates that the component imposes the excess cost to the system. Therefore, it can be an option to make it less efficient and affordable without any significant harm to the system's efficiency. Thus, this factor is a useful tool to recognize which component can be improved by lowering its cost. Furthermore, if the exergoeconomic factor is too low, it means exergy destruction of the component costs too much, and this component needs to work more efficient thermodynamically.

As it is observed in Table 15, the exergoeconomic factor of combustion chamber and whole GT package is quite low. The exergoeconomic factor of combustion chamber, process heat exchanger and HRSG pack are 4.31, 0.09 and 18.71 percent, respectively. Thus, in order to prevent excess cost by destruction of exergy, one of the appropriate options to improve the system can be increasing the efficiency of these components.

Relative cost difference of the equipment indicates the fraction of product's cost to that of fuel for each component. Therefore, as it gets larger, the product of the equipment becomes more expensive. So the components with the highest relative cost difference are good targets to be investigated in order to diminish extra costs they take.

As the results of Table 15 illustrate, process heat exchanger and desalination units have the highest value of relative cost difference. Therefore, they are the most capable components to be considered to reduce their costs because these components lead to the most expensive products relative to their input fuel.

The exergoenvironmental factor indicates the relation between the environmental impact rate of the equipment and the environmental impact made by the exergy destruction as shown in equation (15). Air compressor, combustion chamber, process heat exchanger and HRSG have the lowest values of exergoenvironmental factor. Considering the definition of this parameter, it could be recommended to invest cost on these components in order to diminish the environmental impact they exert.

The exergy destructed by combustion chamber costs $629.78 \$ / \mathrm{h}$ and makes $261.18 \mathrm{pts} / \mathrm{h}$ environmental impact. This result illustrates the importance of exergy destruction in this component and proposes to lower this destruction by improving its performance thermodynamically and reduce its irreversibility. 
Table 15. Investment cost rate, exergoeconomic factor and relative cost difference, environmental impact rate, exergoenvironmental factor, relative environmental impact difference and exergetic efficiency of the equipment

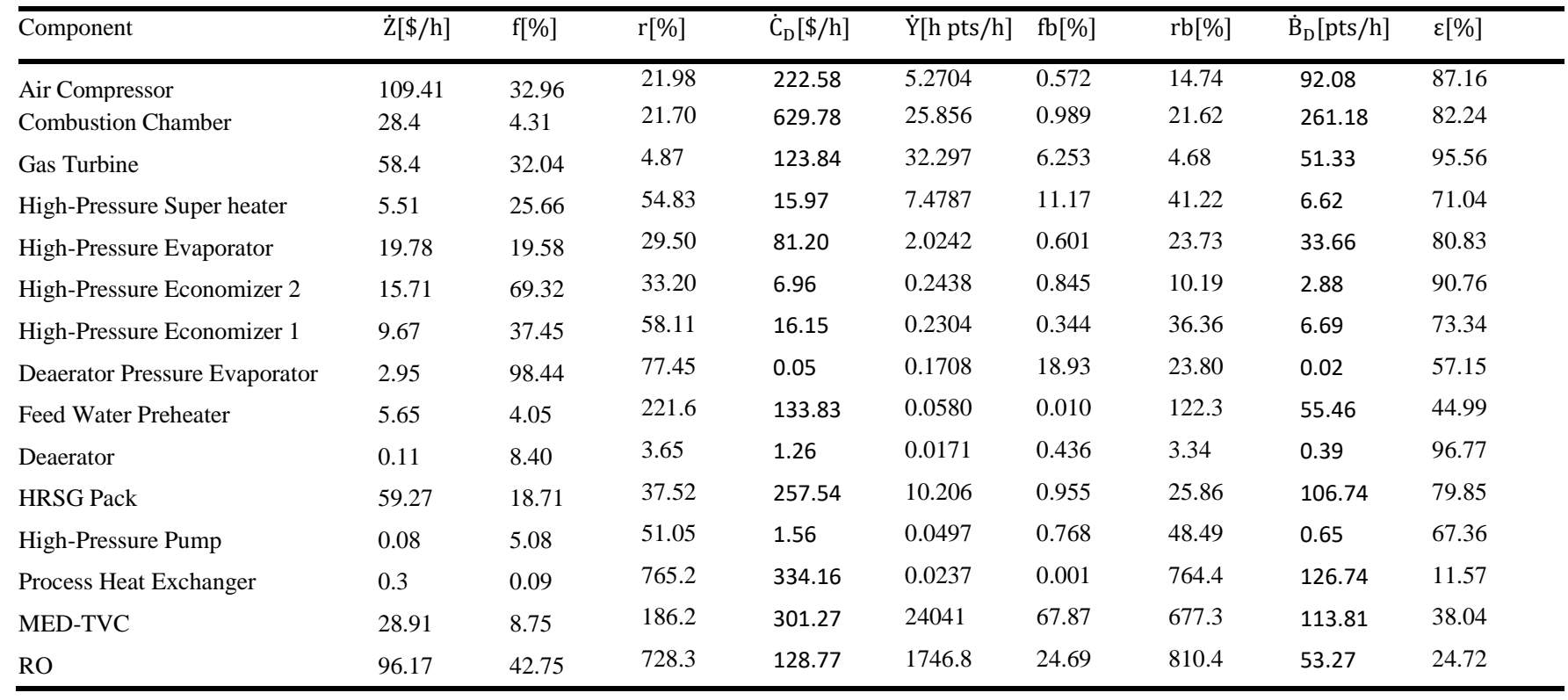

\section{Conclusion}

Exergy destruction of the equipment drains a significant amount of useful energy in the components, and also it exerts excess cost and undesired environmental impact to the system. Amongst the components, combustion chamber, heat recovery steam generator and process heat exchanger have the highest values of cost and environmental impact due to the destruction of exergy. Moreover, the exergoeconomic and the exergoenvironmental impact factors of these components have been determined as the smallest ones. Referring the concepts of these parameters, as discussed in the results section, it is recommended to consider a priority for lowering these components' irreversibility by improving their performance through spending money. This will make the system work more cost effective by preventing the cost squandered through exergy destruction.

Integrating the existing MED-TVC desalination unit of Qeshm power and water cogeneration system with RO unit has led to an increase of 255.12 tons per hour in distillate production. Exergetic efficiency, total cost rate of the system and total environmental impact rate of the system has been calculated $46.86 \%, 64.01 \$ / \mathrm{min}$ and $29.49 \mathrm{pts} / \mathrm{min}$, respectively. Proposing a new scheme for the existing system or/and conducting an optimization process for the system can afford new opportunities to improve the efficiency of the system. Since the largest share of exergy destruction rate of the system belongs to the gas cycle and also Qeshm Island has a warm and muggy climate, adding a chiller type air cooling system to inlet of air compressor can decrease the power demand of air compressor. Regarding the assumption that net power output of the system is constant, gross power produced by gas turbine and fuel consumption by combustion chamber will dwindle by this alteration. Lowering the fuel consumption in combustion chamber leads to diminish the exergy destruction of the gas cycle, thereby increasing the efficiency of the system and decreasing total cost and environmental impact rate of the system. These proposals can be evaluated quantitatively in the further studies performed on this case study.

\section{Data Availability}

Some data, models, or code generated or used during the study are available from the corresponding author by request.

\section{Nomenclature}

$\begin{array}{ll}\text { A } & \text { Area } \\ \text { AC } & \text { Air Compressor } \\ \text { B } & \text { Brine } \\ \text { b } & \text { environmental impact per exergy unit } \\ \dot{B} & \text { environmental impact rate } \\ \text { bm } & \text { environmental impact per mass unit } \\ \text { c } & \text { cost per exergy unit } \\ \text { CC } & \text { Combustion Chamber } \\ \dot{C} & \text { cost rate } \\ \text { COND } & \text { Condenser } \\ \text { cp } & \text { specific heat at constant pressure } \\ \text { Cr } & \text { compression ratio } \\ \text { CRF } & \text { Capital Recovery Factor } \\ \text { D } & \text { Distillate } \\ \text { DE } & \text { Deaerator } \\ \text { DPEV } & \text { Deaerator Pressure Evaporator } \\ \dot{E} & \text { Energy rate } \\ \text { Er } & \text { expansion ratio } \\ \text { ex } & \text { specific exergy } \\ \dot{E} x & \text { Exergy rate } \\ \text { f } & \text { exergoeconomic factor } \\ \text { F } & \text { Feed } \\ \text { fb } & \text { exergo-environmental factor } \\ \text { FWPH } & \text { Feed Water Preheater } \\ \text { GOR } & \text { gained output ratio } \\ \text { GT } & \text { Gas Turbine } \\ & \end{array}$


HPEV High-pressure Evaporator

HPP High-pressure Pump

HPSH High-pressure Super Heater

HRSG Heat Recovery Steam Generator

J specific mass flow rate

LHV Lower Heating Value

$\dot{m} \quad$ Mass Flow Rate

MED multiple effect desalination

$\mathrm{Mr} \quad$ Mixing Ratio

MW molecular weight

n number of effects

$\mathrm{N} \quad$ annual operating hours of the system

NS Nominal Size of TVC

ny operating years of the system

$\mathrm{P} \quad$ Pressure

PEC Purchase Equipment Cost

PR Performance Ratio

Q Heat Duty

r relative cost difference

$\mathrm{rb}$ relative environmental impact difference

$\bar{R} \quad$ Universal Gas Constant

RO reverse osmosis

rp Pressure ratio

RR Recovery Ratio

S entropy

SA specific area

T Temperature

TIT Turbine Inlet Temperature

TVC thermal vapor compressor

U overall heat transfer coefficient

W work

w weight

$\mathrm{x} \quad$ mole fraction

$\mathrm{X} \quad$ salinity

y environmental impact of the component

$\dot{Y} \quad$ environmental impact rate of the equipment

$\dot{Z} \quad$ Cost rate of the equipment

\section{References:}

[1] I. C. Karagiannis and P. G. Soldatos, "Water desalination cost literature: review and assessment," Desalination, vol. 223, no. 1-3, pp. 448-456, 2008.

[2] J. E. Miller, "Review of water resources and desalination technologies," Sandia national labs unlimited release report SAND-2003-0800, 2003.

[3] E. Mathioulakis, V. Belessiotis, and E. Delyannis, "Desalination by using alternative energy: Review and state-of-the-art," desalination, vol. 203, no. 1-3, pp. 346365, 2007.

[4] C. Charcosset, "A review of membrane processes and renewable energies for desalination," Desalination, vol. 245, no. 1-3, pp. 214-231, 2009.

[5] M. A. Eltawil, Z. Zhengming, and L. Yuan, "A review of renewable energy technologies integrated with desalination systems," Renewable and Sustainable Energy Reviews, vol. 13, no. 9, pp. 2245-2262, 2009.

[6] K. P. Lee, T. C. Arnot, and D. Mattia, "A review of reverse osmosis membrane materials for desalination-
Greek Letters

$\Delta$

$\varepsilon$

$\eta$

$\varphi$

$\rho$

$\Pi$

subscripts

fg

$\mathrm{c}$

cwd

D

e

$\mathrm{F}$

$\mathrm{fb}$

fh

fw

$\mathrm{gc}$

hp

i

$\mathrm{k}$

$\mathrm{P}$

$\mathrm{S}$

sat

sub

sup

sw

superscripts

$\begin{array}{ll}* & \text { restricted dead state } \\ 0 & \text { global dead state } \\ \mathrm{CH} & \text { Chemical } \\ \mathrm{PH} & \text { Physical }\end{array}$

development to date and future potential," Journal of Membrane Science, vol. 370, no. 1-2, pp. 1-22, 2011.

[7] S. Porada, R. Zhao, A. Van Der Wal, V. Presser, and P. Biesheuvel, "Review on the science and technology of water desalination by capacitive deionization," Progress in materials science, vol. 58, no. 8, pp. 1388-1442, 2013. [8] L. F. Greenlee, D. F. Lawler, B. D. Freeman, B. Marrot, and P. Moulin, "Reverse osmosis desalination: water sources, technology, and today's challenges," Water research, vol. 43, no. 9, pp. 2317-2348, 2009.

[9] F. Banat, "Economic and technical assessment of desalination technologies," in IWA Conference-New Technologies for Water and Wastewater Treatment in the 21st Century, Geneva, Switzerland, June, 2007, pp. 6-8.

[10] D. Conti, "Thermodynamic and Economic Evaluation of Co-Production Plants for Electricity and Potable Water," Project paper, Polytechnic of Milan, 2003.

[11] L. Garcia-Rodriguez, "Seawater desalination driven by renewable energies: a review," Desalination, vol. 143, no. 2, pp. 103-113, 2002. 
[12] A. Subramani and J. G. Jacangelo, "Emerging desalination technologies for water treatment: a critical review," Water research, vol. 75, pp. 164-187, 2015.

[13] T. Matsuura, "Progress in membrane science and technology for seawater desalination-a review," Desalination, vol. 134, no. 1-3, pp. 47-54, 2001.

[14] D. M. Warsinger, J. Swaminathan, E. GuillenBurrieza, and H. A. Arafat, "Scaling and fouling in membrane distillation for desalination applications: a review," Desalination, vol. 356, pp. 294-313, 2015.

[15] H. Sharon and K. Reddy, "A review of solar energy driven desalination technologies," Renewable and Sustainable Energy Reviews, vol. 41, pp. 1080-1118, 2015.

[16] S. Tadros, "A new look at dual purpose, water and power, plants-economy and design features," Desalination, vol. 30, no. 1, p. 613, 1979.

[17] M. Darwish, F. A. Yousef, and N. Al-Najem, "Energy consumption and costs with a multi-stage flashing (MSF) desalting system," Desalination, vol. 109, no. 3, pp. 285-302, 1997.

[18] N. M. Wade, "Energy and cost allocation in dualpurpose power and desalination plants," Desalination, vol. 123, no. 2-3, pp. 115-125, 1999.

[19] M. Darwish, "Co-generation power desalting plants: new outlook with gas turbines," Desalination, vol. 161, no. 1, pp. 1-12, 2004.

[20] E. Cardona and A. Piacentino, "Optimal design of cogeneration plants for seawater desalination," Desalination, vol. 166, pp. 411-426, 2004.

[21] Y. Wang and N. Lior, "Performance analysis of combined humidified gas turbine power generation and multi-effect thermal vapor compression desalination systems-Part 1: The desalination unit and its combination with a steam-injected gas turbine power system," Desalination, vol. 196, no. 1-3, pp. 84-104, 2006. [22] Y. Wang and N. Lior, "Performance analysis of combined humidified gas turbine power generation and multi-effect thermal vapor compression desalination systems: part 2: the evaporative gas turbine based system and some discussions," Desalination, vol. 207, no. 1-3, pp. 243-256, 2007.

[23] M. Khoshgoftar Manesh, M. Amidpour, and M. Hamedi, "Optimization of the coupling of pressurized water nuclear reactors and multistage flash desalination plant by evolutionary algorithms and thermoeconomic method," International Journal of Energy Research, vol. 33, no. 1, pp. 77-99, 2009.

[24] S. E. Shakib, M. Amidpour, and C. Aghanajafi, "Simulation and optimization of multi effect desalination coupled to a gas turbine plant with HRSG consideration," Desalination, vol. 285, pp. 366-376, 2012.

[25] A. Alzahrani, J. Orfi, and Z. Alsuhaibani, "Performance analysis of a gas turbine unit combined with MED-TVC and RO desalination systems," Desalination and Water Treatment, vol. 55, no. 12, pp. 3350-3357, 2015.

[26] B. Suleiman, A. Olawale, and S. M. Waziri, "Exergetic and Economic Assessment of Distillation Hybrid Configurations for Bioethanol Refining," International Journal of Thermodynamics, vol. 17, pp. 221-231, 12/01 2014.

[27] A. S. Hanafi, G. M. Mostafa, A. Fathy, and A. Waheed, "Thermo-Economic Analysis of Combined
Cycle MED-TVC Desalination System," Energy Procedia, vol. 75, pp. 1005-1020, 2015/08/01/ 2015.

[28] N. M. Eshoul, B. Agnew, and R. Z. Mathkor, "Thermodynamic analysis of combined cycle power plant standalone and coupled with multi effect desalination with thermal vapor compression," in IREC2015 The Sixth International Renewable Energy Congress, 2015, pp. 1-6: IEEE.

[29] B. Suleiman, A. S. Abdulkareem, U. Musa, I. A. Mohammed, M. A. Olutoye, and Y. I. Abdullahi, "Thermo-economic analysis of proton exchange membrane fuel cell fuelled with methanol and methane," Energy Conversion and Management, vol. 117, pp. 228240, 2016/06/01/ 2016.

[30] N. Eshoul, A. Almutairi, R. Lamidi, H. Alhajeri, and A. Alenezi, "Energetic, Exergetic, and Economic Analysis of MED-TVC Water Desalination Plant with and without Preheating," Water, vol. 10, no. 3, p. 305, 2018.

[31] K. Owebor, C. O. C. Oko, E. O. Diemuodeke, and O. J. Ogorure, "Thermo-environmental and economic analysis of an integrated municipal waste-to-energy solid oxide fuel cell, gas-, steam-, organic fluid- and absorption refrigeration cycle thermal power plants," Applied Energy, vol. 239, pp. 1385-1401, 2019/04/01/ 2019.

[32] M. A. Esmaeilzadehazimi, M. H. Khoshgoftar Manesh, B. Heleyleh, and H. Modabbaer, "4E Analysis of Integrated MHD-Combined Cycle," International Journal of Thermodynamics, vol. 22, pp. 219-228, 11/29 2019.

[33] J. Kucera, Desalination: water from water. John Wiley \& Sons, 2019.

[34] M. Ohkawara, G. Nemoto, Y. Kansha, A. Tsutsumi, M. Ishizuka, and H. Mizuno, "Seawater desalination device and seawater desalination method," ed: Google Patents, 2019.

[35] H. Wang, "Low-energy desalination," Nature nanotechnology, vol. 13, no. 4, p. 273, 2018.

[36] A. Bejan, G. Tsatsaronis, M. Moran, and M. J. Moran, Thermal Design and Optimization. Wiley, 1996.

[37] I. Dincer, M. A. Rosen, and P. Ahmadi, Optimization of Energy Systems. Wiley, 2017.

[38] I. Dincer and M. A. Rosen, "Chapter 3 - Chemical Exergy," in Exergy (Second Edition), I. Dincer and M. A. Rosen, Eds.: Elsevier, 2013, pp. 31-49.

[39] M. H. Sharqawy, S. M. Zubair, and J. H. Lienhard, "Second law analysis of reverse osmosis desalination plants: An alternative design using pressure retarded osmosis," Energy, vol. 36, no. 11, pp. 6617-6626, 2011/11/01/ 2011.

[40] E. J. C. Cavalcanti, "Exergoeconomic and exergoenvironmental analyses of an integrated solar combined cycle system," Renewable and Sustainable Energy Reviews, vol. 67, pp. 507-519, 2017/01/01/ 2017. [41] M. Goedkoop, R. Spriensma, S. Effting, and M. Collignon, The Eco-indicator 99: A Damage Oriented Method for Life-cycle Impact Assessment: Manual for Designers. PRé, Product Ecology consultants, 2000.

[42] G. Raluy, L. Serra, and J. Uche, "Life cycle assessment of MSF, MED and RO desalination technologies," Energy, vol. 31, no. 13, pp. 2361-2372, 2006/10/01/ 2006.

[43] A. Valero et al., "CGAM problem: Definition and conventional solution," Energy, vol. 19, no. 3, pp. 279286, 1994/03/01/ 1994. 
[44] K. H. Mistry, M. Antar, and J. H. Lienhard V, An improved model for multiple effect distillation. 2012, pp. $1-15$.

[45] A. S. Hassan and M. A. Darwish, "Performance of thermal vapor compression," Desalination, vol. 335, no. 1, pp. 41-46, 2014/02/17/ 2014.

[46] A. Al-Zahrani, J. Orfi, Z. Al-Suhaibani, B. Salim, and H. Al-Ansary, "Thermodynamic Analysis of a Reverse Osmosis Desalination Unit with Energy Recovery System," Procedia Engineering, vol. 33, pp. 404-414, 2012/01/01/ 2012.

[47] H. Ghaebi, M. H. Saidi, and P. Ahmadi, "Exergoeconomic optimization of a trigeneration system for heating, cooling and power production purpose based on TRR method and using evolutionary algorithm," Applied Thermal Engineering, vol. 36, pp. 113-125, 2012/04/01/ 2012.

[48] F. A. Boyaghchi and P. Heidarnejad, "Thermoeconomic assessment and multi objective optimization of a solar micro CCHP based on Organic Rankine Cycle for domestic application," Energy Conversion and Management, vol. 97, pp. 224-234, 2015/06/01/ 2015.
[49] Y. M. El-Sayed, The Thermoeconomics of Energy Conversions. Elsevier Science, 2013.

[50] C. Park et al., "Stochastic cost estimation approach for full-scale reverse osmosis desalination plants," Journal of Membrane Science, vol. 364, no. 1, pp. 52-64, 2010/11/15/ 2010.

[51] W. Zhou, L. Song, and T. K. Guan, "A numerical study on concentration polarization and system performance of spiral wound RO membrane modules," Journal of Membrane Science, vol. 271, no. 1, pp. 38-46, 2006/03/01/ 2006.

[52] M. Ameri, P. Ahmadi, and A. Hamidi, "Energy, exergy and exergoeconomic analysis of a steam power plant: A case study," International Journal of Energy Research, vol. 33, no. 5, pp. 499-512, 2009/04/01 2009. 